\title{
VENEZUELA, LOS CAMBIOS GLOBALES Y SU POLÍTICA EXTERIOR
}

\author{
Carlos A. Romero*
}

\section{INTRODUCCIÓN}

A partir de los cambios globales, se le abren grandes posibilidades a las políticas exteriores de los países latinoamericanos, al igual que se le presentan innumerables retos. La complejidad de la reciente estructura internacional, los nuevos temas, el avance tecnológico y las nuevas dimensiones del comercio internacional son, entre otros, algunos de los elementos que resaltan a la hora de diseñar e implementar respuestas nacionales a un mundo en el cual la incertidumbre, la disparidad entre los deseos y las realidades y la confusión de identidades limitan la calidad de las políticas y van en contra de sus propias innovaciones (Rosenau 1996).

América Latina no es ni debe ser indiferente a esos cambios. En nuestras Cancillerías se debate sobre el rumbo que debe tomar la diplomacia regional. Para algunas de ellas, no cabe más que ajustarse a los dictámenes de Washington. Para otras, deberían reinventarse los esquemas de integración y recobrarse un espíritu de cooperación regional. Para el resto, vale la pena esperar y no comprometerse con un camino determinado.

En este marco, la globalidad nos remite a un cierto consenso sobre un nuevo contexto internacional en donde los Estados van paulatinamente compartiendo su papel con otros actores multilaterales y transnacionales, y en donde las economías nacionales dejan de ser tales conectándose con otros actores a través de una interdependencia compleja dentro de una red única de mercados y producción y la reformulación de la agenda mundial. De esta manera, "La situación actual se caracteriza por una gran complejidad de elementos, contrastes y contradicciones, sinergías y conflictos..." (Naciones Unidas, CEPAL 1996, p. 24).

Las transformaciones anotadas, las cuales se resumen en la idea de que vivimos en la época de la post - Guerra Fría, encuentran a América Latina dentro de un proceso de superación de algunas de sus limitaciones políticas y económicas. La "Década Perdida", la hipertrofia de los autoritarismos de los setenta, la obsolescencia de su aparato productivo, la distribución regresiva del ingreso, la presencia del peso de la deuda externa y el poco protagonismo internacional, posibilitan que en los últimos años, los gobiernos de la región acepten que la integración económica sea una alternativa confiable para superar los obstáculos al desarrollo y para insertarse en la globalización (Fernández 1996).

Para llegar a alcanzar ese objetivo, se estima que es necesario consolidar los sistemas democráticos y cambiar el paradigma tradicional económico, el tan citado "Modelo Cepalista" de los años cincuenta, en donde el Estado, las políticas de industrialización, la sustitución de las importaciones y el crecimiento hacia adentro jugaron un papel fundamental. Así, se aspira a lograr el "Buen Gobierno y la Integración Económica" en el contexto de un nuevo paradigma económico basado en las premisas de la desregulación y la coordinación económica (Sánchez 1997, SELA 1997).

Si bien, los cambios "afuera" son más importantes que los cambios "adentro" en la región, desde este ángulo no son pocos los esfuerzos para lograr una respuesta viable a los retos actuales. Así, se destaca el impulso a la cooperación regional a través de la integración económica. Esta se determina por "su dimensión, los elementos que incluye: su profundidad, la búsqueda de políticas de armonización, su institucionalización y su centralización" (Peter Smith 1992 p. 5). Esta cooperación lleva a la concreción del proceso de regionalización en la esfera gubernamental a través de los acuerdos respectivos y las asociaciones de carácter público; en la esfera económica privada, a través del impulso de un mercado libre de bienes, servicios y de inversión, además de las alianzas estratégicas; y en la esfera societal, a través del desarrollo de múltiples canales que llevan a la creación de una sociedad civil regional de perfil transnacional (Hurrell 1994).

En este contexto la agenda de integración latinoamericana ha conocido desde la década de los sesenta, varios esquemas de integración: la ALAC, el Pacto Andino, CARICOM, el Mercado Común Centroamericano, y varios esquemas de cooperación económica como la ARPEL, la AEC, el SELA, el Grupo de Río y el Grupo de los Tres. En la actualidad, entre los más importantes se tienen el nuevo Pacto Andino, "el Grupo Andino" y Mercosur. Por otra parte, desde una perspectiva hemisférica, se tienen el NAFTA y el ALCA (Tulchin 1997, Ramos 1997).

En este sentido, la mayoría de los gobiernos latinoamericanos han comprendido que las políticas individualistas y

\footnotetext{
* Profesor de Ciencia Política de la Universidad Central de Venezuela
} 
aislacionistas del pasado ya no tienen una razón de ser en el mundo globalizado. De hecho, las agendas de las políticas exteriores han dado un importante giro. De esta forma, resaltan, los intentos de integración ya mencionados, la promoción del comercio intra-regional, el flujo de inversiones extranjeras, la apertura de las economías y la protección ambiental.

Desde el punto de vista político, cabe destacar el proceso de fortalecimiento de la democracia, la lucha contra la corrupción y la defensa de los derechos humanos, la preocupación por la estabilidad política regional, el terrorismo, el narcotráfico y las relaciones cívicas - militares. Desde el punto de vista económico, se tiene el desarrollo de un nuevo modelo de crecimiento hacia afuera, pero a la vez, la competencia desleal, las limitaciones a la libre exportación de productos, las asimetrías y la creciente pobreza y migración (Pries 1997).

En este contexto, merecen destacarse ciertas tendencias que se observan en la actualidad y que pueden convertirse en un conjunto de limitaciones al proceso de integración. Frente a la idea de una mayor complementación política y una posible comunidad latinoamericana de naciones, se debe tener en cuenta "la calidad" de los sistemas políticos. Es decir, que frente a la idea kantiana de la paz perpetua lograda tal vez a través de la integración, se levante un estado de cosas como la presencia de una cultura política populistanacionalista-estatista, el localismo político y a su vez, la importancia de la sociedad civil. Por otra parte, no está claro si América Latina debe sostener una alianza hemisférica con los EE.UU o por el contrario buscar unan mayor acercamiento con la Unión Europea y con el resto del mundo (Romero 1996).

$\mathrm{Al}$ analizar y proyectar las maneras por medio de las cuales Venezuela se está adaptando a esas nuevas condiciones, no se está realizando un mero ejercicio de conocimiento estéril o la multiplicación de un saber convencional que asuma conceptos y discursos de moda. Por el contrario, este ejercicio presupone la discusión y la confrontación teórica sobre la mejor manera de comprender las posibilidades y limitaciones que presenta esa relación entre los cambios globales, el producto principal de exportación y el régimen democrático en Venezuela (Krugman 1996).

Esa rápida y compleja transformación de los escenarios internacional y regional constituye un importante reto intelectual tanto como de gobernabilidad para analistas y decisores públicos en el ámbito de la política exterior de Venezuela. La agenda actual de problemas mundiales, la proliferación de temas y de nuevos actores plantean serios desafíos para nuestro país.

En este trabajo se analiza como ésta nueva realidad influye en la política exterior de Venezuela y en definitiva como esta puede adaptarse al mundo de la globalización.

Un paso inicial para abordar esta problemática nos lleva a plantear al menos cuatro premisas teóricas, indispensables en el desarrollo de este ejercicio, premisas que nos orientarán en la conformación de varias de las áreas de discusión que queremos desarrollar. En primer término, abordamos como necesaria la tesis de que estamos en un mundo en transición en el cual los criterios tradicionales para el estudio de la política limitan la comprensión de nuevas realidades y procesos. Llamamos criterios tradicionales aquellos derivados de la Edad Moderna, específicamente de la Ilustración, que se basan en la idea del Estado como forma política fundamental, de la soberanía como la condición jurídica principal en las relaciones entre los Estados y sus ciudadanos, y de la racionalidad instrumental como el instrumento básico para regular las relaciones entre gobernantes y gobernados. De esta manera, se entiende que la política presenta dos fases diferenciadas. Aquella que establece un tipo de vinculación especial con el mundo exterior y que se concibe como las relaciones internacionales, y la otra, vinculada con la política interna, con los asuntos domésticos.

Una segunda premisa descansa en la idea que ese mundo en transición se puede conocer solo a través de una visión amplia del fenómeno político que supere tanto la dicotomía entre lo externo y lo interno como la idea de un mundo solo de Estados y de instituciones amparadas por la ley. En este marco, resalta la Teoría de la Complejidad. En efecto frente a una realidad fragmentada, confusa y llena de incertidumbre, surge la pregunta de cómo evaluarla. Como dice Rosenau, "Si las épocas anteriores se entendían en términos de tendencias centrales y patrones ordenados, la época presente parece derivar su orden de tendencias contrarias y patrones episódicos. Si una vez se pensó que las vidas de los individuos y las sociedades se movían en trayectorias lineales y estables, ahora los movimientos parecen no lineales y erráticos, con equilibrios momentáneos e interrumpidos continuamente por súbitas aceleraciones o cambios de dirección" (Rosenau 1996, p. 5). Por ello, frente a la simultaneidad y las interconexiones de los acontecimientos, se hace necesario realizar un esfuerzo de comprensión múltiple de partes relacionadas entre sí y que son altamente sensibles.

Una tercera premisa permite precisar que el comportamiento de los decisores y de la masa, entendido este concepto en su dimensión sociológica, (por cierto olvidada por la presencia del individualismo), no puede limitarse a los criterios emanados de la racionalidad pura, sino que a la hora del análisis hay que tomar en cuenta todo un campo lleno de riqueza teórica que es el de la irracionalidad; los símbolos, los mitos, las creencias colectivas, las imágenes, lo virtual, todo aquello que sostiene el mundo de las percepciones y de lo que llamó Popper, "el tercer mundo", aquel plano de la realidad que ni es propiamente material ni tampoco inmaterial (Krugman 1996, p. 715).

Una cuarta y última premisa que es necesario determinar para abocarnos en esta tarea de relacionar la globalidad con la política exterior de Venezuela, se basa en la idea de la importancia de la degradación de la política como palanca fundamental para el ejercicio del poder. Esta degradación parte de la constatación de un crecimiento de otras esferas consideradas de bajo perfil político, como la economía o el ambiente, de la competencia de otros actores distintos al Estado para dirigir las sociedades, y de un rechazo creciente a la manera de hacer política (tanto autoritaria como democrática) a través de los partidos y de las instituciones, eso que se ha llamado la anti-política, la política informal, o la post-política (Rivas Funes 1995). En referencia a este tema 
surgen los conceptos de sociedad civil y de organizaciones no gubernamentales, así como también los temas del medio ambiente, la descentralización, los derechos humanos y la participación que, sin ánimo de desconceptualizarlos como provenientes de una raigambre liberal, nutren el discurso de la anti-política, altamente competitivo del discurso tradicional basado en la primacía del Estado, los partidos políticos y el político como instrumentos claves del poder.

Con base en esas cuatro premisas, transición, complejidad, irracionalidad y post-política, consideramos posible abordar nuestro problema, tal es el de relacionar tres variables que se entrecruzan, los cambios globales, el petróleo y la política exterior en un caso de estudio específico, el de Venezuela.

\section{EL CASO VENEZOLANO}

Se puede abordar desde tres ángulos. Por una parte tenemos el papel del petróleo como el puente histórico contemporáneo entre Venezuela como actor internacional y el resto del mundo. En segundo lugar, los efectos de la globalización en la industria petrolera mundial y en la industria petrolera venezolana, y en tercer lugar, los efectos de los cambios globales en la vida política y social del país.

En cuanto a lo primero, el tema se ha abordado a través de un discurso dominante cuyas premisas se basan en las siguientes consideraciones: somos un país petrolero, confiable (a Occidente), con una economía rentista y con un Estado poseedor y distribuidor de ese ingreso a través del cobro de la renta petrolera.

Con base a esos términos, el petróleo ha sido el principal vehículo para nuestra inserción en las relaciones internacionales contemporáneas, tanto desde del punto de vista de nuestra ventaja competitiva como por los efectos secundarios de esa inserción; modernidad, progreso, industrialización, proteccionismo, e igualitarismo. Este conjunto de factores han promovido a su vez una cierta cultura política considerada como estatista, facilista y poco impulsadora de la actividad privada, los riesgos de la "enfermedad holandesa", la dependencia de la sociedad civil del Estado y la vulnerabilidad del país ante las oscilaciones de los precios del barril del petróleo, tanto a nivel mundial como a nivel del barril de petróleo venezolano.

En términos generales y con variados matices, el impacto del petróleo en el país se ha evaluado negativamente, y se ha aspirado a "sembrar el petróleo", es decir aprovechar los ingresos petroleros a fin de diversificar la economía, manteniendo criterios conservacionistas con relación a la explotación equilibrada de las reservas petroleras. En este marco, el debate petrolero estuvo dominado por un discurso estatista, en primer término, bajo las políticas de no más concesiones y participación fiscal del Estado venezolano; y luego, desde la década de los setenta de este siglo, bajo la política de nacionalización de la industria. Desde la perspectiva internacional, Venezuela ha respaldado la acción de los productores de petróleo a través de la OPEP y ha mantenido al petróleo como una de las columnas en que se desarrolla su política exterior.
Ahora bien, los cambios globales están afectando también a la industria petrolera como tal. Por una parte, el mercado petrolero mundial se está transformando en cuanto al número de productores, inclusive en mayor término que los miembros de la OPEP y en el acercamiento del mundo árabe a Occidente, con lo cual se cuestiona la premisa "del país más confiable”. En segundo lugar, la incorporación de nuevas tecnologías productivas y organizacionales obligan a la empresa estatal matriz petrolera del país, Petróleos de Venezuela PDVSA y a sus filiales, a iniciar transformaciones estructurales en su esquema tradicional de empresa vendedora de crudos y bajo un esquema organizacional de empresa vertical "fordista", hacia la búsqueda de mercados seguros, nuevos conceptos de mercado y productos y nuevos esquemas administrativos, organizacionales y laborales basados en las nuevas concepciones de red empresarial, reingenería y otros (PDVSA 1996).

Una mención especial se merecen los procesos de internacionalización y privatización de PDVSA. En cuanto a la internacionalización, esta ha significado una presencia mayor internacional de la industria venezolana en áreas del negocio nuevas para Venezuela como el mercadeo, así como también en los que se refiere a impulsar una mayor autonomía de la industria de la OPEP. En referencia a la privatización, iniciar este proceso significa impulsar la llegada a Venezuela de una inversión extranjera calificada que bajo diversas formas, asociaciones, joint ventures, ganancias compartidas, y licitaciones, reinterpretan el discurso estatista tradicional.

El rompimiento con el discurso tradicional de no más concesiones y estatismo de la industria, más el impulso de la exploración y explotación por la vía de la asociación con compañías extranjeras significa un impacto muy grande del petróleo sobre la sociedad venezolana. Mencionemos tan sólo tres claves para nuestra indagación: la cancelación en la práctica de la discusión sobre si Venezuela es petrolera y debe buscar con la siembra del petróleo y una economía distinta. Pareciera que el reimpulso de la industria petrolera en Venezuela, define como petrolero al país sin ningún tipo de complejos. Por otra parte, se observa una especie de nuevo boom petrolero que si bien no beneficia a toda la economía a través del gasto público, como fue en décadas anteriores, impulsa ciertos sectores de la economía local, además del impacto que significa el retorno de las compañías petroleras extranjeras y conexas con la industria, en áreas de servicio. Por último, pero no menos importante, hay que destacar el impacto del petróleo, bajo estas nuevas condiciones en la vida política venezolana.

La relación entre los cambios globales y el impacto de estos en la industria petrolera conforman un conjunto de intereses, procesos, imágenes y discursos que de manera directa están y estarán afectando la vida política venezolana. Tres son las principales áreas en las cuales podemos ubicar esta relación.

En primer lugar, se observan los cambios en el propio sistema político. De ser un sistema estatista y centralista dominado casi absolutamente por los partidos y los dirigentes políticos partidistas, nos encontramos hoy con un sistema de características mixtas, el cual presenta y presentará rasgos tradicionales, por el papel del Estado y de la economía 
rentista, pero también rasgos distintos muy en sintonía con los grandes temas políticos mundiales, tales como la descentralización, la participación ciudadana y la apertura política hacia esquemas menos partidistas enmarcados en la sociedad civil y en la descentralización política (Romero 1998).

En segundo lugar, se tienen los retos que debe asumir la política exterior en términos de la heterogeneidad creciente de las instituciones y decisores que tienen que ver con la posición internacional del país. Si bien, la fragmentación exterior es una característica de los Estados en la actualidad, tanto desde el punto de vista de las competencias ministeriales a nivel central, como desde el punto de vista de las instancias descentralizadas y la participación de organismos multilaterales y no gubernamentales, en Venezuela, el papel del petróleo impulsa a que PDVSA juegue un rol fundamental, junto con la Cancillería, el Ministerio de Industria y Comercio y el Ministerio de la Defensa en el frente externo del país. Esto a su vez impulsa el desarrollo de una discusión sobre el papel internacional que debe jugar el país en el marco de los cambios globales, y su grado de presencia activa. (Sobre esto se abre un debate interesante sobre el tipo de activismo; si el tradicional de permanecer y actuar en organismos como Naciones Unidas o la OPEP y en países tradicionales, o buscar la presencia en organismos multilaterales nuevos como la OMC e impulsar la presencia de Venezuela en países emergentes).

En tercer lugar, hay que señalar que la multiplicación de actores internacionales y nacionales convierten el proceso de negociación social en algo mucho más complejo, y que los factores irracionales comienzan a jugar un papel predominante a la hora de analizar el apego del ciudadano a la política y al Estado. Considérese por ejemplo que hasta hace pocos años, la vinculación del ciudadano hacia la política era de carácter utilitario e ideológico. En los tiempos actuales, estos dos instrumentos han dado paso a mecanismos emocionales más difíciles de evaluar.

Desde el punto de vista de su política exterior, Venezuela en los últimos años se ha caracterizado por tener una diplomacia pragmática abierta a varias opciones en donde se destaca: 1) el impulso del perfil petrolero, 2) la incorporación "con desgano" a los esquemas de integración comercial, Comunidad Andina, AEC, ALCA; 3 ) la rivalidad intra - burocrática entre el Ministerio de Relaciones Exteriores, el Ministerio de Industria y Comercio y la empresa estatal petrolera (Petróleos de Venezuela, PDVSA) por el control de la agenda de la política exterior; 4) el acercamiento a Mercosur a través de Brasil; 5) el desarrollo de unas relaciones comerciales difíciles con los EE.UU. (Romero 1998, Cardozo de Da Silva 1997).

\section{GLOBALIZACIÓN Y POLÍTICA EXTERIOR: EL CASO VENEZOLANO}

Ya se da un consenso en las relaciones internacionales, acerca de que son más las preguntas que las explicaciones que genera este proceso de transición mundial. Descartada la idea de que es una anomalía lo que no calza en el parámetro dominante que es el Realismo, en la disciplina se acepta que, por ejemplo la dicotomía entre la tradición y la modernidad ya no tiene sentido, como tampoco lo tiene la visión particular, parroquial, excepcional de un caso en particular. Ahora, por el contrario, se entiende que hay diferentes resultados y que el camino correcto para la investigación es la comparación (Andrew Janos 1986: 58).

Desde la década de los sesenta, se pretendía un cambio paradigmático. En el campo marxista, se quiso trasladar la idea de división del trabajo dentro de una sociedad a una división del trabajo mundial (ya no la lucha por el poder entre estados soberanos sino la lucha por recursos escasos, entre pobres y ricos); y la idea de la interdependencia desde una perspectiva liberal.

Desde esta perspectiva, la crítica a la preponderancia del Estado - Nación como el único actor internacional va ligada a una propuesta teórica, tal es de aceptar que "las viejas fórmulas ya no satisfacen en gran medida porque han dejado de corresponder a la manera cómo ahora se ve el mundo" (Elliot 1991). Por ello, la visión dominante que enfatizaba lo interno sobre lo externo a la hora de preguntarse cómo se podrían insertar las naciones en desarrollo al mundo actual dio paso a un interrogante: hasta que punto y de qué manera se podría reconocer la importancia del contexto internacional para explicar el desarrollo político (Almond, 1992: 263).

En América Latina, así como en otras áreas geográficas, se experimentó el debate sobre el desarrollo en iguales circunstancias. Luego de observarse signos de agotamiento en las experiencias modernizadoras, en las experiencias socialistas y en las variadas combinaciones tercermundistas, comenzó a generarse un debate que exigía una mejor comprensión de un mundo que iba hacia la globalización, hacia nuevas tecnologías y esquemas organizacionales, hacia planos multilaterales y transnacionales y nuevas formas de pertenencia nacional y grupal. De esta manera, "la globalización la podemos vislumbrar como un proceso multidimensional que pone en interacción a las diversas sociedades, Estados y regiones del planeta de una manera desigual, tanto a nivel internacional como nacional" (Fazio Vargas 1997).

El nuevo contexto internacional exige entonces un cambio para los Estados- Nación. Claro está que este reacomodo tiene diversos grados de asimetría y diversas respuestas. Es cierto que se dio un menú general de opciones seguido por los países latinoamericanos (con excepción de Cuba): reducción del gasto público, la promoción de inversiones extranjeras, las privatizaciones, la estabilización del tipo de cambio, la eliminación de los aranceles, y el fomento de la inversión privada (Fazio Vargas 1997: 34). Pero también es cierto que algunos países trataron de dar sus respuestas singulares. Uno de ellos fue Venezuela.

En efecto, dentro de los mitos que ha tenido la política en Venezuela, el mito de la excepcionalidad es uno de los más importantes. Junto con los mitos de Bolívar, de la solidaridad internacional, del petróleo, de la democracia, la creencia en que Venezuela es distinta, es singular, ha pesado mucho en la toma de decisiones. Esta manifestación de desconfianza hacia las nuevas tendencias políticas dificulta entonces la relación entre el mundo en transición y el deterioro del 
orden político en Venezuela. Novedades como el orden político transnacional, las interacciones entre los mercados globales y el Estado - Nación, el fenómeno de las migraciones, la personas desplazadas, los refugiados, los ciudadanos duales, las identidades múltiples, las lealtades y las interacciones societales emergen como puntos problemáticos.

En este marco, interesa conocer los antecedentes, el desarrollo y los alcances de un modelo político que descansa en las ideas de ser un país democrático y petrolero y que abarca dentro de un proceso complejo un nuevo tipo de hacer política. Si bien otros países han podido acceder a este proceso lentamente o por el contrario, bruscamente (como los países europeos ex - socialistas), en el caso de Venezuela la ruptura no ha podido concretarse a pesar de las fisuras de sistema político y en la economía internacional, con sus secuencias claras de inestabilidad política y reducción de precios del barril del petróleo venezolano.

\section{LA CONFORMACIÓN DEL ESTADO VENEZOLANO}

En una y otra ocasión, América Latina ha sido objeto de estudio por la politología occidental. Durante la década de los cincuenta en particular, la región se incluyó dentro de los estudios sobre el desarrollo político y económico y el cambio social en el mundo subdesarrollado. En un primer período predominó una visión institucionalista, la cual planteaba la necesidad de crear esquemas constitucionales e institucionales lo suficientemente fuertes para superar los tradicionales regímenes caudillistas y militaristas. En una segunda etapa, principalmente luego de la publicación de un interesante artículo de S. M Lipset, titulado "Some Social Requisites of Democracy", los estudios sobre América Latina avanzaron hacia una visión sociológica en donde se enfatizaba que si se lograba un desarrollo económico, se podía llegar a tener un sistema democrático funcionando plenamente. De esta forma, "en el mundo moderno, el desarrollo económico que incluye a la industrialización, la urbanización, altos niveles de educación y un crecimiento sostenido de la riqueza de un país, es una condición básica para la democracia, es un logro central de la eficiencia de todo el sistema" (Lipset, 1959: 86).

Sin embargo, la llamada "ecuación optimista", tal como se le conoció a este argumento, no logró ocultar un hecho indiscutible: que en la región no se emulaban los modelos occidentales. En este marco surgieron dos tipos de interpretación. O se estimaba que por razones patológicas era difícil alcanzar los parámetros del desarrollo político racional-legal occidental o que, tarde o temprano, debido a la adopción racional de esos patrones, se lograría un desarrollo institucional (Schmitter 1975).

De esta manera, se fundamentaron dos tipos de discurso académico sobre América Latina: una visión optimista basada en la necesidad y la pertinencia de la modernidad y una visión pesimista basada en la tesis sobre la presencia de un conjunto de obstáculos al desarrollo político y económico entendiéndose esto último como la constatación de una anomalía congénita (Almond 1990).
Sin embargo, ambos discursos, los cuales tenían como premisa común la pertinencia del modelo occidental, no lograron analizar y comprender a la política latinoamericana como un fenómeno propio y no como anomalías o desviaciones del patrón aludido. De esta forma, se estaba llegando a la conclusión que "los países latinoamericanos probablemente no estén desarrollando a la larga la misma senda" (Schmitter 1975: 54).

Como consecuencia del surgimiento y el desarrollo de los regímenes autoritarios, de la desaparición o estancamiento de los modelos democráticos y de la constatación de la carencia de los requisitos a los cuáles se había referido Lipset, se fue conformando una visión menos simplista sobre los alcances de la democracia en la región. Esto también estaba pasando en el resto del mundo subdesarrollado, tal como lo planteó en su momento y de manera bastante clara Samuel Huntington en su libro "No Easy Choice" cuando enfatizó la idea que el crecimiento económico no llevaba necesariamente al desarrollo político (Hirschman 1979: 68, Huntington).

¿Cómo enfrentar teóricamente las limitaciones a la democracia en América Latina desde una perspectiva comparada? ¿Por qué, tal como lo sugirió Schmitter, "el desarrollo social y económico había inhibido la participación y había promovido la concentración y la relativa independencia de la autoridad estatal?" (Schmitter 1975: 56).

La respuesta no se hizo esperar. A fines de la década de los sesenta varios analistas de América latina comenzaron a dudar sobre los alcances de la ecuación optimista para comprender nuestra realidad destacándose dos escuelas de pensamiento. En primer lugar, aquella conocida como la de la Dependencia que enfatizaba el carácter de subordinación de América Latina al mercado capitalista mundial y la imposibilidad de emular la senda occidental democrática; y en segundo lugar, la escuela del Autoritarismo que enfatizaba el carácter autoritario de la política regional bien en su versión populista o en su versión burocrática militar, esta última planteada como necesaria para la profundización del capitalismo. En consecuencia, la historia de América Latina se podría observar a través de una línea recta imaginaria, un continuo cuyos extremos son el populismo y el autoritarismo (O’Donnell 1973; Malloy 1977).

Para esclarecer lo que significaba ese continuo, O'Donnell y otros importantes especialistas en política comparada de América Latina plantearon que los regímenes autoritarios eran compatibles con la modernización, que el populismo y sus elementos fundamentales (Anti-imperialismo, Justicia Social, Policlasismo y Estado fuerte) habían fracasado y que la profundización del capitalismo dependiente y tardío exigía un pluralismo limitado en el marco de una política de austeridad excluyente, despolitizando a las masas y limitando sus expectativas sociales y económicas. Así, América Latina no había alcanzado el modelo liberal occidental (Estado débil, mercado político, sociedad civil, racionalidad), sino más bien un modelo estatista y corporativista (O’Donnell y Schmitter 1986).

De la misma manera que había pasado con el populismo, las expectativas sobre el modelo burocrático-autoritario también se vieron reducidas por la descomposición social 
y la represión que trajo la aplicación del modelo, dándose así una serie de críticas sobre que la profundización del capitalismo exigía una senda autoritaria. Pero hay algo más: también se propagó una serie de críticas sobre el excesivo economicismo de esas tesis. Por una parte, O`Donnell había olvidado las variables políticas que sirvieron para instaurar los modelos autoritarios y en segundo lugar, las variables internacionales (Linz 1978; Schmitter 1986).

En la década de los ochenta, diversos analistas comenzaron a plantear la necesidad de buscar una respuesta a la decadencia del modelo burocrático autoritario, o bien la salida constitucional o bien la salida pactada. En este sentido, se hacía necesario repensar la relación entre la modernización y el cambio político, y la reestructuración de la sociedad civil. En ese marco, el modelo venezolano, equidistante entre el populismo y el autoritarismo comienza a ser observado seriamente.

Si bien la perspectiva autoritaria contribuyó al análisis sobre el derrumbe del populismo y el surgimiento del modelo burocrático autoritario en la década de los sesenta, no quedó claro que ese modelo obedeciera a una circunstancia concreta, el agotamiento del populismo latinoamericano y que la profundización del capitalismo se podía emprender bajo otro esquema basado en el neoliberalismo económico y en la apertura política. Se criticó entonces el rol del Estado en la economía, el corporativismo presente en las relaciones sociales y el autoritarismo presente en la toma de decisiones (Reina 1994).

En síntesis, los estudios sobre América Latina han transitado por varias etapas: en las décadas de los cincuenta y parte de los sesenta predominó una visión optimista basada en la tesis de Lipset, "desarrollo económico igual a desarrollo político"; en la década de los setenta, una visión pesimista basada en la idea de la profundización del capitalismo solo a través del autoritarismo, y en la década de los ochenta y en los noventa, una visión optimista que descansaba en la idea de la descentralización política, la crítica al Estado regulador, a la misma política y los partidos, y la promoción de la sociedad civil (Cardozo de Da Silva 1995).

En este marco, el caso venezolano ha sido difícil de incluír de manera satisfactoria en las clasificaciones generales comparadas sobre regímenes políticos en la región (Levine 1973; Romero, C 1992).

Por mucho tiempo, el modelo venezolano, el Sistema Político Venezolano (SPV), se consideró como un ejemplo para las propuestas de transición del autoritarismo hacia las democracias pactadas, aunque se criticó desde diferentes ángulos. En la actualidad, la complejidad del modelo vuelve a confundir a quienes estudian sus fundamentos y sus posibilidades de mantenerse en el futuro. Si antes no era lo demasiado autoritario para incluírlo dentro de la perspectiva burocrática-autoritaria, hoy significa para algunos autores un sistema demasiado autoritario y corporativizado para clasificarlo como democrático (Romero, C 1998).

El sistema político venezolano (SPV) tiene unos supuestos básicos desde la óptica racional: es un modelo de democracia presidencialista, con una economía mixta, un sistema de partidos, elecciones periódicas y libertad política. Por otra parte, se destacan tres tendencias socio-ecónomicas: la importancia de la renta petrolera, una distribucion ampliada del ingreso, y un papel central del Estado en la economía. $\mathrm{Y}$ en tercer lugar, se mantiene un grupo de mitos políticos que sustentan el modelo: el mito del progreso de la población por vivir en un país petrolero, el mito de que el venezolano es esencialmente democrático y el mito del clientelismo. Estos a su vez tienen sus símbolos: las becas, el voto y la tarjeta de recomendación (Van der Dijs 1993; Capriles 1993).

El Sistema experimentó una gran crisis en los años 1992 y 1993 y todavía presenta fisuras en su gestión, sobre todo en el área económica. Sin embargo, no hubo un cambio significativo de sus estructuras ni sus supuestos, a pesar de que dos de sus principales indicadores, el crecimiento económico para todos y el apego a la democracia se derrumbaron por la aparición de una inflación significativa y un desencanto político expresado en una alta abstención electoral.

Entonces surge una pregunta crucial: si los fundamentos del Sistema son cuestionados, y si el apego a la democracia tiene un descenso porcentual, ¿por qué el Sistema ni se ha caído, ni ha habido una ruptura constitucional, ni se ha transformado en un sistema más abierto?

La respuesta no es fácil, dada la complejidad del SPV, pero fundamentalmente dada la presencia de un problema teórico: en referencia al estudio del SPV, la mayoría de los enfoques politológicos dominantes no han dado cuenta de sus específicas condiciones, y siguiendo nuestro argumento central, no han incorporado al análisis el vasto campo de la irracionalidad política (Martin G.; Rey 1980; Romero, A.; 1997).

En este marco, se tienen cuatro enfoques principales: el enfoque proveniente del campo histórico-político, que ha enfatizado el rol de los partidos políticos y de los dirigentes políticos democráticos en la fundamentacion del sistema político y que denominaremos, el enfoque Martz, en referencia al autor más representativo de esta corriente, el venezolanista norteamericano John Martz. Esta perspectiva ha observado al SPV como el producto de la competencia electoral de partidos de diversas ideologías y de la hegemonía de Acción Democrática, y en menor medida de Copei sobre la política venezolana. De esta visión se desprenden cuatro razonamientos generales: el venezolano se identifica con la política a través de los partidos y sus líderes; los criterios de asociación del venezolano son fundamentalmente seculares; no hay clases definidas ni diferencias étnicas significativas; Venezuela es un país homogéneo e integrado.

El segundo enfoque tiene un carácter economicista, resultado de la tradición marxista en el país y enfatiza el carácter dependiente de la sociedad venezolana y el criterio clasista de la élite dominante, el cual denominaremos el enfoque CENDES, en referencia al instituto de investigación del mismo nombre de donde han salido importantes publicaciones con esta orientación. Esta perspectiva enfatiza los procesos socio-económicos como la clave para entender a la política venezolana, en sintonía con criterios como la violencia política, la marginalidad y la pobreza, el gasto público, el rol del Estado en la economía y la distribución del ingreso (Kornblith 1996). De esta perspectiva se desprenden cuatro razonamientos: en Venezuela hay una gran diferencia entre los logros de la democracia y la vida económica del venezolano; somos un país dependiente de los Estados Unidos; el 
sujeto político en Venezuela no sólo son los partidos sino el pueblo. El Estado venezolano controla la vida política.

Un tercer enfoque de carácter político e institucional enfatiza el papel de las élites en la constitución del SPV y lo denominaremos el enfoque Rey, en honor a su principal exponente, el politólogo venezolano Juan Carlos Rey. Este enfoque es el más utilizado entre los autores venezolanos dedicados al estudio del SPV y fundamenta su análisis con la tesis sobre que el SPV es el producto de un pacto, en el marco de un sistema populista de conciliación de élites. De esta perspectiva que enfatiza el criterio político para entender el SPV, se desprenden tres razonamientos: el sujeto de la política en Venezuela no son si los partidos ni el pueblo, son las élites; éstas han logrado un consenso capaz de estabilizar la vida política a través del usufructo del ingreso público y su distribución equitativa; lo importante es analizar los criterios racionales que permiten ese consenso y el apoyo popular. Esto supone: 1) una alta capacidad de negociación; 2) un estilo conciliador de negociación; 3) una alta desmovilización, debido principalmente al control de las mismas a través de organizaciones confiables. Para Rey y sus seguidores, el SPV está en crisis ya que ha fallado el consenso inter-élites, no se genera una confianza de la población en las élites, se da una crisis sociopolítica y un frustrado intento de poner unas nuevas reglas de juego políticas (Rey 1991)

Dentro de esta perspectiva, se ha utilizado en menor grado otro enfoque, el neoliberal, éste último en boga en años recientes. Sus seguidores asumen que el SPV está agotado y que debe suplantarse por un liderazgo de la sociedad civil frente al Estado y una descentralización política, enfatizando el rol del ciudadano en la política y observando una crítica a los partidos y otras organizaciones corporativistas. A este lo denominaremos el enfoque COPRE, ya que es en esta Comisión Presidencial para la Reforma del Estado en donde se ha producido un mayor número de publicaciones que se orientan en la dirección neoliberal (Kornblith 1996). Asi tenemos cuatro enfoques principales con sus respectivas variables: Partidos, Estado, Elites y Sociedad Civil.

¿Qué tienen en común estos enfoques? En términos generales, los que los une es su preocupación por analizar los mecanismos explícitos y racionales que conforman un determinado perfil del sistema político venezolano. En este sentido, el enfoque Martz le da prioridad al sistema de partidos y a los mecanismos electorales; el enfoque Cendes a la gestión estatal; el enfoque Rey a la negociación entre las Elites y el enfoque Copre a la participación ciudadana. En este marco, (con excepción de algunos autores que se basan en el enfoque Cendes), estas perspectivas no contemplan el análisis de factores irracionales en la política venezolana, y si lo hacen, como es el caso de los estudios sobre corrupción, clientelismo y gasto del Estado, lo consideran como una desviación del sistema y no como una característica propia del mismo (Alvarez 1981).

\section{HACIA LA CONSIDERACIÓN DE UN MODELO ALTERNATIVO}

Recordemos dos planteamientos generales mencionados previamente: en primer lugar, que el análisis de la polí- tica latinoamericana ha descansado fundamentalmente en un ciclo dicotómico pesismista y positivo. En segundo lugar, que esas perspectivas no han tomado en cuenta, o en algunos casos, no han privilegiado la presencia de elementos irracionales en la política, y si se le ha prestado atención ha sido a través de su consideración como desviaciones del modelo racional-legal (Almond 1990).

¿Cómo pudiera colocarse el caso venezolano en el marco de esta reflexión? ¿Cuáles son los principales elementos irracionales en el SPV? ¿Cómo se puede conocer verdaderamente al SPV?

En cuanto lo primero, tenemos que son cinco los principales elementos irracionales en el SPV, los cuáles a su vez tienen una gran importancia para entender el porqué el Sistema no se ha regenerado plenamente, vale decir, no ha vuelto al esquema populista de conciliación; ni se ha transformado, con base a la participación ciudadana y la descentralización de la política, ni ha sido suplantado por otro, a través de un golpe militar o una revolución.

Estos son: 1) en contraposición de la idea generalizada que el venezolano es esencialmente racional a la hora de votar, de apoyar al sistema o de pronunciarse "por la mejor forma de vida, la democracia”, su relación con la política es más compleja. La cultura política imperante es la del clientelismo, la del compadrazgo, el de las cadenas familiares en la burocracia, la del individualismo. Esto permite disentir de las tesis neoliberales que asumen la racionalidad perfecta del ciudadano. 2) los mitos políticos que sostenían en parte al SPV han perdido su fuerza, "en Venezuela no hay inflación y en el país la gente vota”. Casos concretos: La exigencia de los gremios de mejoras salariales; el desdén del elector por la política tradicional dada la circunstancia que ya no es necesario pertenecer al partido x para obtener prebendas. 3) otro elemento irracional del SPV es el fenómeno de la corrupción. Esta no puede verse de manera tradicional, es decir como una desviación del SPV. Por el contrario, es un elemento fundamental para el sostenimiento del Sistema. Casos concretos: la repartición de los contratos en el seno del Congreso Nacional cuando se aprueba el presupuesto; los fueros sindicales. 4) por otra parte, se tiene que tomar en cuenta el rol del ingreso petrolero. Los enfoques "Martz, Cendes, Rey y Copre" insisten en lo negativo para el SPV de la conformación del Estado rentista. Por el contrario sostenemos que es el Estado rentista la razón de ser del SPV. 5) como consecuencia de la crisis política experimentada en los años 91, 92 y 93, se ha extendido la creencia que el SPV ha experimentado grandes transformaciones hacia la participación y la descentralización. Sospechamos por el contrario que el proceso político venezolano ha afianzado su carácter autoritario (Karl 1997).

Con base a las consideraciones anteriores tenemos que dos son las claves para entender el carácter irracional del SPV: por una parte, el clientelismo y el compadrazgo, y por la otra, la dependencia del gasto público de los ingresos petroleros. En este sentido, vale la pena explorar cuáles son claves para entender porqué el SPV no ha sido superado por nuevas formas de democracia o sustituído por un régimen militar o revolucionario. Se sugieren tres elementos: 1) la paradoja de poseer una mayor estabilidad del sistema, y a 
su vez un reflujo del apego a la política y en menor medida a la democracia por parte de los venezolanos. En consecuencia, la crítica de las Elites a la violencia política popular, lo que sostuvo la tesis de los años sesenta de controlar las expectativas de la población. En el fondo, las Elites no están preparadas para el cambio (Almond 1990). "Venezuela es una taquilla", como sabiamente exclamó en un momento de angustia un ex-Presidente de la República. Esto significa que el gasto público nunca dejará de crecer mientras se mantenga la red clientelar.

Todo esto nos lleva a insistir en la necesidad de utilizar, a la hora del análisis del Sistema Político Venezolano, un modelo alternativo diferente a los enfoques tradicionales. Ese modelo alternativo tiene que incluir en sus supuestos algunos de los elementos ya mencionados así ćomo otros que se verán a continuación. De esta manera, se tendrá una panorámica más nítida del SPV y una mayor fuerza teórica y metodológica para abordarlo.

Para empezar, este modelo alternativo tiene que "descontruir" la tendencia cronólogica líneal que ha dominado el análisis histórico contempóraneo en nuestro país, en donde se ha enfatizado, por una parte, que el sistema democrático es una etapa superior al pasado dictatorial, y por la otra, la tendencia a unificar los eventos históricos a través de los períodos presidenciales, dejando de lado la posibilidad de comprender eventos diversos no causales ni necesariamente homogéneos. Al mismo tiempo, es necesario clarificar la posición que se tiene frente al problema, como se escojen los datos y los modelos teóricos y metodológicos (Romero, 1997).

En función de afinar los elementos que componen ese modelo alternativo, sería útil analizar cuatro importantes publicaciones escritas por autores que han querido evaluar al SPV de una manera diferente y que les une un interés común, el de relacionar el SPV con la específica condición rentística venezolana, lo cual permite observar con más claridad los vinculos entre la política y el petróleo en Venezuela.

Antes de analizar estas obras, debe recordarse que la tendencia fundamental en la historiografía sobre el petróleo en Venezuela es la de remarcar una idea pesimista sobre la relación entre política y petróleo. El tono de denuncia, la influencia del nacionalismo y el antiimperialismo, la percepción sobre los efectos nocivos del petróleo sobre la economía junto con el visón del sistema político como populista y clientelar, van conformando un cierto tipo de definición negativa sobre esa relación (Rodríguez Gallad 1974, Urbaneja 1990). Sobre este punto, el joven investigador Martín Durán ha clasificado ocho grupos de autores venezolanos que se han preguntado sobre el destino de la renta petrolera. En palabras de Durán, "tenemos: 1) los correspondientes al período gomecista como Vicente Lecuna, Gumersindo Torres y Alberto Adriani, 2) un autor post-gomecista no adeco como Arturto Uslar Pietri, 3) dos autores creadores de la visión "adeca" es decir, Rómulo Betancourt y Juan Pablo Pérez Alfonso, 4) tres que siguen la corriente socialcristiana como Hugo Pérez La Salvia, Humberto Calderón Berti y Rafael Caldera, 5) tres autores que suscriben el materialismo histórico, tales como Francisco Mieres, Bernardo Mommer y Carlos Mendoza Potellá, 6) cuatro correspondientes a la corriente liberal o neoliberal, en este caso se involucra a Gustavo Coronel, Ricardo Haussman, Emeterio Gómez, Alberto Quiróz-Corradi, 7) dos autores que suscriben la llamada visión de PDVSA como lo son Luis Giusti y Andrés Sosa Pietri y 8) un grupo en el que se incluyen cuatro autores cuyos estudios no parecen involucrarse en una visión sesgada de la realidad, ellos son Asdrúbal Baptista, Luis Pedro España, Diego Bautista Urbaneja y María Sol Pérez Schael” (Durán 1998).

La historiografía sobre el petróleo en Venezuela se ha enriquecido en los últimos años con el aporte de valiosas obras que tratan de superar la visión simplista sobre los efectos perversos del "oro negro", sobre el proceso político venezolano y que tratan de puntualizar como la dirección política y económica del país ha manejado esa relación de una cierta forma. En este sentido, de lo que se trata es de ubicarse más allá del plano estructural, vale decir en el plano de las políticas públicas, en la esfera de las decisiones públicas y de la responsabilidad política (Jones..., Pérez Schael 1993).

En estas publicaciones, los autores precisan que es en el tema de la renta petrolera en donde se puede analizar mejor en que consiste el tipo de política (Polity) que está presente en el caso venezolano. Esto en sí permite ampliar los enfoques Martz, Rey y Copre, efectivamente orientados a privilegiar las variables políticas, y el enfoque Cendes, orientado a periodizar las variables económicas.

La primera obra que se va analizar es el libro escrito por Diego Bautista Urbaneja titulado "Pueblo, Petróleo y Política" (Urbaneja 1990). En este sugerente escrito, Urbaneja se pregunta en primer lugar que piensan las Elites sobre el pueblo y como cada una de las corrientes ideológicas presentes en la historia de las ideas en Venezuela (liberal, positivista, marxista y democrática) responden a ese tema. En un segundo término, el autor especifica que en Venezuela estamos en la presencia de un Estado rentista el cual no tiene la misión redistribuitiva ya que no extrae recurso de la sociedad, sino que por el contrario distribuye una riqueza no producida por la sociedad. De esta forma, la sociedad no mantiene al Estado sino ésta a la sociedad, en el marco de un rentismo sociológico que impulsa una autonomía mayor del Estado (Urbaneja). Este tipo de rentismo contribuye a formar un tipo de política en Venezuela tendiente a promocionar la movilidad social fuertemente controlada por los partidos políticos, a limitar la participación popular y alcanzar el consenso político y la conformación de un pacto político populista, el "sistema de negociación social" (Urbaneja 1990).

De los planteamientos de este autor, se pudieran tomar cuatro elementos centrales para contribuir a la conformación de un modelo alternativo a los enfoques citados previamente. Estos elementos son: 1) El Estado venezolano distribuye la renta petrolera y no redistribuye la riqueza de la sociedad; 2) El Estado rentista limita la posibilidad de una expansión democrática en el país; 3 ) la idea de "sembrar el petróleo" debe asumirse a través de la "prisa" histórica de aprovechar el recurso natural y los ingresos fiscales que origina la renta petrolera.

Una segunda publicación importante de mencionar es el libro escrito por María Sol Pérez Schael titulado "Petróleo Cultura y Poder en Venezuela" (Pérez Schael 1993). En su obra, la autora discute el predominio de una visión pesimista 
sobre el petróleo y su relación con el país a través de un exhaustivo análisis de los aportes de Alberto Adriani, Arturo Uslar Pietri, Rómulo Betancourt y otros autores provenientes del mundo jurídico y literario que se dedicaron a reflexionar sobre el petróleo en Venezuela. En este marco, la autora nos recuerda como para Adriani la agricultura y el desarrollo capitalista de ese sector de la economía se ve afectado por la aparición de la industria petrolera perteneciente al área de la minería, algo no duradero y destructivo. Para Uslar Pietri, la moral venezolana se corrompe con el petróleo de ahí la necesidad de "sembrar el petróleo", vale decir, de aprovechar de invertir los recursos petroleros en la producción. Para Betancourt, la culpa de los males venezolanos es la presencia de las compañías petroleras extranjeras y el Imperialismo.

En un segundo tramo del libro, María Sol Pérez Schael analiza la relación entre mina y petróleo, enfátizando el papel de la jurisprudencia española la cual equipara mina con recurso petrolero. De esta forma, se oscurece la realidad de que se entrega, el producto y no la mina (Pérez Schael). Por ello, la sociedad venezolana se va estructurando con base a lo que la autora llama "el abuso organizado de poder" originándose..." un proceso de distribución en el cual no solo se daba acceso a la riqueza (dinero) sino también el derecho a vivir como si fuera propietario, es decir, derecho a beneficiarse de un bien, sin contraparte o cambio alguno" (Pérez Schael 1993).

De las ideas expuestas en el libro en cuestión se pueden extraer tres elementos centrales: 1) la confusión entre mina y petróleo como producto lo lleva a que se considere a este último como una renta; 2) la idea de que el petróleo no ha sido sembrado, lo que no permite analizar los logros colectivos (Esto es, la presencia de un complejo de inferioridad colectivo); 3) la precisión sobre que el petróleo no tiene la culpa de que el proceso histórico venezolano no presente los resultados esperados (Pérez Schael 1993).

Ramón Espinasa es otro de los autores contemporáneos que vale la pena mencionar. En su artículo "Petróleo y Desarrollo" publicado en 1993, y en la monografía "Política Petrolera y Desarrollo Económico", publicado en 1997, el autor plantea que la relación entre el petróleo y la sociedad venezolana ha tenido dos grandes orientaciones. Por una parte, se ha considerado al petróleo como enclave extranjero y como industria nacionalizada, maximizando la renta petrolera. Por la otra, la industria petrolera se ha integrado recientemente a la apertura del sector a la inversión privada y estimulando la expansión sostenida de la actividad productiva (Espinasa 1993 y 1997).

Estas orientaciones se dan en el marco de dos factores claves: el ingreso fiscal petrolero y la actividad petrolera. En la primera fase rentística, se entendió que: 1) había una escasez de reservas petroleras; 2 ) que estas reservas estaban en manos foráneas; 3) se daba una separación de la industria petrolera del país. En la segunda fase no rentística, se estima que: 1) la industria debe integrarse internamente; 2) que hay reservas cuantiosas; 3) que la industria debe vincularse al país. En este sentido se trata de pasar de una política esencialmente rentista a una política productiva, la actividad petrolera se valora a si misma y no tan solo como fuente de ingresos. De ahí se deriva la apertura petrolera, la apertura del mercado interno, la restructuración de PDVSA, los convenios operativos, las asociaciones estratégicas, los convenios de exploración a riesgo y los Fondos de Inversión (Espinasa 1997).

Desde un ángulo político, Espinasa al igual que Urbaneja y Pérez Schael contempla la relación entre la política y el petróleo en Venezuela de esta forma: "la transferencia neta de recursos externos que representa la renta petrolera le ha permitido al sector no-petrolero tener un ingreso mayor que el que se corresponde con su producto" (Espinasa 1997:31). A su vez, el tipo de cambio se convierte en un instrumento de distribución de la renta petrolera. Esto da como resultado un esquema de subsidios en donde el ingreso petrolero, la tasa de cambio, y el gasto público lo alimentan constantemente. Así, a mayor devaluación, mayor costo para el consumidor, a mayor apreciación mayor subsidio y transferencia a los consumidores. Por ello, un Estado fuerte, un mayor gasto público más un bajo nivel impostivo y divisas baratas distorsionan la relación entre el petróleo y la sociedad venezolana.

De este autor podemos extraer dos elementos: 1) que la tasa de cambio es la palanca fundamental para la distribución del ingreso petrolero y no el gasto público, como tradicionalmente se venía observando al caso venezolano; 2 ) que para entender las recientes transformaciones del Sistema Político Venezolano hay que tomar en cuenta el proceso devaluador de la moneda venezolana (Espinasa 1997).

Terry S. Karl publicó en 1993 otro excelente libro sobre el tema que nos ocupa titulado "The Paradox of Plenty: Oil Booms and Petro-States" (Karl 1997). Karl asume varias de las tesis previamente reseñadas por Urbaneja, Pérez Schael y Espinasa, pero contribuye a colocarlas en una perspectiva comparada en donde el caso venezolano es observado junto con otras economías petroleras (Karl 1997).

En el comienzo del libro, Karl se pregunta porqué los países subdesarrollados petroleros han experimentado casi de idéntica forma un proceso de deterioro económico e incertidumbre política, aún operando en contextos geopolíticos diferentes, con estrategias de desarrollo idénticas, trayectorias semejantes y resultados perversos (Karl 1997: XV). Seguidamente, la autora se pregunta si eso es inevitable, si se reduce, sin capacidad de prevenirlo, el rango para la toma de decisiones o se debe a errores cometidos en la implementación de la política. En este contexto, Karl discute dos problemas centrales a este tipo de economía. Los efectos perversos de la llamada "Enfermedad Holandesa" (el proceso por medio del cual un crecimiento exponencial de un sector de la economía deprime el resto a los otros), lo que produce a la larga un estancamiento general de la economía. En este sentido, los países exportadores de petróleo subdesarrollados, exacerban la dependencia de una economía de un producto. En segundo término, para la autora, el origen de los ingresos públicos influye en la conformación de las instituciones públicas: el Estado, el Régimen y el Gobierno. El Estado es la estructura organizacional permanente (la burocracia y las instituciones) el régimen marca las estrategias a seguir para las toma de decisiones y el gobierno consiste de los actores (políticos partidistas, administradores 
civiles y admistradores militares) que ocupan posiciones dominantes dentro del régimen en un determinado momento" (Karl 1997: 14). Por ello, es el Estado, y no el sector privado, el centro de acumulación beneficiado por la renta petrolera. Esto produce un comportamiento rentista de la sociedad, lo que lleva a: 1) la petroleorización del ambiente político; 2) la resistencia al cambio por parte de la mayoría de una sociedad protegida y subsidiada (Esta relación es clave para entender la crisis del año 1989, en el contexto de un nuevo gobierno que se planteaba reducir el tamaño del Estado, la importancia de los subsidios y el gasto público); 3) un crecimiento desmedido del Estado.

Por otra parte, la autora se opone a la tesis del excepcionalismo venezolano basada en las premisas del enfoque Rey (elecciones periódicas, pactismo, partidos políticos y consenso). Según Karl, esta visión es incompleta ya que no toma en cuenta el problema del acceso a la renta petrolera. A su vez, esta Venezuela de pactos reforzó la renta petrolera desde 1958, dando lugar a "una democracia sin perdedores" (Karl 1997: 111).

El último pero no menos importante libro que se reseña es el escrito por Asdrúbal Baptista titulado "Teoría Económica del Capitalismo Rentístico. Economía, Petróleo, Renta" (Baptista 1997).

El autor ahonda en el problema de la renta petrolera, de una economía que recibe una clase de ingreso que "demanda y cobra el propietario de unos instrumentos útiles para la actividad productiva, los cuales, por su parte, no son el resultado de ningún proceso productivo" (Baptista 1997: 9). En este marco, "este tipo de economía no tiene una contrapartida productiva y la renta se capta en vez de producirse" (Baptista 1997: 38). Al mismo tiempo, Baptista analiza el problema de la tasa de cambio y concluye que en que "la sobrevaluación del bolívar se convierte en un mecanismo de distribución pacífica y popular de la renta internacional" (Baptista 1997: 100).

De esta publicación podemos extraer dos elementos fundamentales: 1) son quienes están en el poder que por voluntad traspasan "los recursos provenientes de la renta petrolera desde el ámbito público a la economía privada" (Baptista 1997: 40); 2) que la tasa de cambio es el elemento fundamental para entender el funcionamiento del Sistema Político Venezolano y no el pactismo (Karl 1997).

En este marco se propone que: la relación entre petróleo y política en la historia reciente del país, particularmente desde la instauración del Sistema Político Venezolano pasa por tres etapas: 1) la primera de ellas va desde 1958 a 1973 y es donde el financiamiento de la política (polity) se basa en la renta; 2) la segunda de ellas va de 1973 a 1989, y es donde el financiamiento se basa en la renta y en la contratación de deuda externa; 3 ) la tercera etapa va de 1989, en donde el financiamiento se basa en la renta, la deuda externa (cada día menos privada externa y más multilateral externa e interna, tanto púbica como privada) y la tributación no petrolera.

Por otra parte, no se puede hablar en Venezuela de un capitalismo "normal". La condición rentística plantea un entorno externo para Venezuela vínculante sobremanera. De hecho, el país está ligado en su proceso histórico al mer- cado petrolero internacional. En segundo término, esa condición genera necesariamente más estatismo, más centralismo y más presidencialismo (España, 1995, Karl 1993).

Con base al análisis anterior, estamos ahora quizás en condiciones de retomar la propuesta teórica sobre la necesidad de ir más allá de los aportes de la racionalidad instrumental para entender el comportamiento del SPV a fin de reexaminar los alcances y las limitaciones de la política exterior de Venezuela, tanto en su dimensión política como económica.

\section{DEMOCRACIA Y PETRÓLEO COMO IDENTI- DADES INTERNACIONALES}

En el marco de las transformaciones que experimenta la estructura internacional, cabe preguntarse acerca de cual es el papel que juega Venezuela en ese proceso, esto implica una revisión de las premisas que sustentan su perfil en el mundo.

Antes de comenzar a explorar esta relación, hay que recordar que el país ha transitado, históricamente hablando, por cinco etapas internacionales. En primer lugar, la referida al descubrimiento y la colonización, período en el cual fuimos descubiertos y conquistados por el Reino de Castilla y Aragón y colonizados por el Imperio Español (en el momento de la expansión de la sociedad internacional), situándonos en el Nuevo Mundo, en América. Una segunda etapa corresponde a la emancipación y consolidación como Estado independiente (dentro del proceso de transición de un sistema de Estados europeos a un sistema de Estados de civilización cristiana); una tercera etapa corresponde a la aparición del petróleo en nuestras tierras (es el período en que se define un sistema de estados civilizados más allá del sistema de estados de civilización cristiana), una cuarta etapa se refiere a la consolidación democrática en el marco de la conformación de la Guerra Fría y una etapa que se refiere al actual periodo en el cual se desarrolla la etapa post- Guerra Fría, de globalización (Elliot 1991, Truyol 1974).

La conformación, desarrollo y cambio en estas cinco etapas han originado un perfil del país en la estructura internacional contemporánea, Somos un país occidental, con un pasado colonial hispánico, situado en América Latina y con dos fuertes identidades, país democrático y petrolero, con amplias relaciones con los Estados Unidos, país hegemónico en el hemisferio occidental (Guerón, E 1983). Esta condición genera a su vez un comportamiento permanente en la política exterior venezolana, el cual como se ve más adelante, se concreta en el desarrollo de cuatro problemas fundamentales: sostener la condición de país democrático y ampliar la condición de país petrolero en relación con Estados Unidos, con los países fronterizos, y con el resto del mundo (Romero 1998). Del mismo modo, se origina un estilo diplomático venezolano, basado en el presidencialismo de su política exterior (lo que incluye la idea de una política exterior homogénea racional y unitaria), el activismo internacional del país (lo que descarta el peso importante de sus vulnerabilidades y una relación positiva con el ambiente externo y el consenso sobre los fines objetivos e 
instrumentos de la misma (lo que supone un proyecto de nación) (Romero 1993; Hillman y Cardozo de Da Silva 1997).

A partir de los cambios globales, tanto Venezuela como el resto de los países que conforman la estructura internacional actual se ven sometidos a fuertes presiones para que se inserte en un mundo cambiante. En este sentido, la reflexión que se ha desarrollado en la teoría de las relaciones internacionales sobre los límites del discurso moderno sobre el papel de la política, el poder, el Estado y la racionalidad, ha llevado a la presente crisis epistemológica y a una proliferación paradigmática. Esto repercute en la reflexión sobre Venezuela y sobre los alcances y limitaciones de su perfil internacional.

Por ello, de cara al año 2000 interesa discutir hasta que punto el binomio que sustenta a la política exterior venezolana -petróleo y democracia- constituye su base fundamental; cual es el impacto de los cambios globales en la formación de esa política y como las transformaciones del sistema político limitan o posibilitan una acción internacional más eficaz y más eficiente. Se trata entonces de someternos a un ejercicio intelectual que permita repensar la experiencia internacional de Venezuela a través de la revisión de sus problemas fundamentales y de la evaluación de sus instrumentos simbólicos y materiales (Vital 1971).

El análisis del contexto internacional actual y su impacto en Venezuela nos conduce a plantear la necesidad de enfocar el problema desde una perspectiva multivariada que incluya no sólo la revisión de los aspectos internos que conforman esa relación sino también sus aspectos externos (Almond 1990). Esto nos lleva a analizar las conexiones entre la discusión sobre el conocimiento actual de las relaciones internacionales y el conocimiento de la política exterior de Venezuela y la discusión sobre la decadencia del Estado y la irracionalidad política.

Son dos las identidades que caracterizan con mayor fuerza a Venezuela en el contexto mundial. Por un parte, Venezuela es un país democrático y por la otra, es un país petrolero. Democrático hasta el punto de constituirse esta identidad como un producto de exportación simbólico; petrolero, para identificarse como un país de carácter estratégico para el mundo occidental. Sobre este perfil, se conforman una serie de objetivos formales y reales.

En cuanto a los objetivos formales, estos serían: i) asegurar y defender la salud del sistema político, ii) mantener un margen de autonomía en la política internacional, iii) diversificar el comercio exterior del país, iv) preservar la integridad del territorio nacional, v) participar activamente en las organizaciones internacionales y otros mecanismos de concertación mundial, vi) defender y promover precios justos y mercados confiables del petróleo venezolano. Los objetivos reales serían: i) mantener unas relaciones estables con los Estados Unidos, ii) contener la posibilidad de los autoritarismos y otras formas políticas no democráticas en América Latina y el Caribe, iii) preservar las fronteras del país.

Con base a lo anterior, Venezuela estaría ubicada en el plano internacional como un país mediano con una capacidad de maniobra simbólica, como país democrático y pacífico, con una capacidad económica, el valor estratégico del petróleo, y con una autonomía periférica (Romero, 1990, Cardozo de Da Silva 1992).

La redimensión de la política exterior de Venezuela está condicionada por las limitaciones y las posibilidades que brinda un momento de transición en la estructura internacional contemporánea y un sistema político en crisis. Esta política tiene como marco de referencia un régimen democrático en donde el recurso petrolero juega un importante papel. Sin embargo, la política exterior presenta un enorme déficit institucional, en la medida en que no se ha adaptado a los requerimientos que exige una diplomacia más moderna, y más participativa.

Primero que todo se origina lo que se ha llamado un déficit de política exterior. En primer lugar, en el plano de los fines y objetivo. En este sentido, no ha habido en los últimos años, un perfil internacional claro, ha sido una política incrementalista (Romero. C, 1998). En segundo lugar, se da un déficit en materia organizacional, porque todo lo que hemos visto anteriormente en cuanto que la política exterior ya no es un monopolio de la presidencia ni del Ministerio de Relaciones Exteriores, hace que otros organismos del Estado tengan cada día una mayor participación no solamente en lo que se denomina la complejidad intraburocrática, sino también que van asumiendo en forma paralela y en nombre del Estado compromisos en nombre del Estado, lo que de una u otra forma atentan contra esa unidad, esa bola de billar de tiempos anteriores. De hecho, ya hay entes en materia de política exterior que están suscribiendo acuerdos que no pasan por la Cancillería tales como el Ministerio de Industria y comercio, la misma PDVSA. En tercer lugar, hay un déficit del aparato de la política exterior, esto quiere decir que se tiene un déficit diplomático. La explosión de intereses, mecanismos, decisiones, acuerdo, y las misma participación de diferente entes en el proceso de formación da lugar a que está sea hoy una política sin personalidad, de transición.

Por ello se hace necesario una política de coordinación entre esos entes y una importante discusión sobre la agenda internacional del país, lo nuevos temas y revisar los socios comerciales.

\section{CONCLUSIONES GENERALES}

Dentro del proceso de los cambios globales, América Latina trata de acortar las distancias que le alejan de una estructura internacional cambiante y compleja, que a partir de la caída del Muro de Berlín y de las transformaciones económicas y tecnológicas citadas plantean un nuevo mundo lleno de incertidumbres, pero a la vez con enormes posibilidades. No todos los países se han adaptado, otros han retomado su perfil internacional occidental como es el caso de Argentina o México, otros luchan por conservar su independencia como Brasil, otros tratan de imponer su agenda, como es el caso de los EE.UU.

América Latina ha encontrado en la integración la vía más expedita para responder a los desafíos de los cambios globales. A través de mecanismos como la Comunidad Andina y Mercosur, la región busca complementarse y for- 
talecerse en bloques, a la vez que negocia la puesta en práctica de una zona de libre comercio hemisférica.

El papel de Venezuela en los procesos de integración de América Latina debe analizarse tanto desde una perspectiva mundial y regional como interna. Para nuestro país, insertarse en los cambios globales ha tenido una respuesta más conservadora que otros países. Esta tendencia conservadora descansa en una estrategia de desarrollo fuertemente vinculada con su condición de país petrolero y confiable como proveedor principal de crudos a los EE.UU. En este sentido, debe recordarse que desde el punto de vista de sus políticas comerciales, el gobierno Caldera suspendió en el año de 1994, el esfuerzo comenzado en el año de 1989 por el gobierno de Carlos Andrés Pérez de apertura económica, y es solo luego de dos años de ejercicio constitucional, en 1996, en que con la puesta en práctica de la llamada "Agenda Venezuela", se trata de corregir los errores cometidos en materia de política monetaria y comercial.

La globalización, el petróleo y la política exterior son tres variables que condicionan la participación de Venezuela en el mundo y en el hemisferio. Su interrelación y proceso tiene que ver con una estructura internacional cambiante, una revaluación de las aproximaciones teóricas y una economía y un sistema político en crisis, en donde la respuesta pública fundamental es la de reivindicar al petróleo como palanca fundamental de desarrollo a través de la internacionalización y privatización de la industria petrolera.

Los llamados cambios globales han repercutido en las relaciones internacionales de dos maneras. Por una parte, la teoría y la práctica de la disciplina ha tenido un importante vuelco, generándose un debate sobre sus alcances y sus limitaciones y su posible transformación en relaciones globales. Por la otra, las políticas exteriores de los Estados que conforman la estructura internacional han tenido que adoptarse a nuevas realidades y a poderosos retos.

En este marco, cabe recordar las ideas esgrimidas por Quentin Skinner sobre el peligro de ubicar la historia de las ideas como algo permanente sin contexto histórico y con segundas intenciones. En efecto, no se trata solamente de analizar los alcances de un debate académico puro sobre si las relaciones internacionales están transformándose en relaciones globales, dada la importancia de nuevos actores, nuevos procesos y nuevos temas. Se trata también de comprender como las ideas políticas son autónomas, imponen limitaciones a la práctica política, colocan en escena unas prioridades y no otras, un vocabulario y no otro, y una manera de ver las cosas y no otra (Skinner, 1998).

En el caso que nos ocupa, se trata de analizar de que manera los términos que dieron lugar a la disciplina se cuestionan actualmente (Carr 1964). Términos como la concepción de las relaciones internacionales como relaciones entre los Estados y el derecho internacional, así como más tarde, el concepto del interés nacional, la problemática del poder político, la separación entre la política doméstica y la política exterior y la visión de las políticas exteriores de los Estados como homogéneas y compactas, como si fueran una "bola de billar". Ahora, como contraposición a estos elementos se esgrime que hay otros actores tan o más importantes que los Estados, que no es posible alcanzar un interés nacional dado la dispersión de compromisos y relaciones exteriores del sector público de un Estado, que la agenda internacional ha dejado de ser una agenda de naturaleza geopolítica para transformarse en una agenda geoeconómica y que la separación ente lo interno y lo externo no tiene sentido en un mundo global.

Vale la pena preguntarse entonces si estos cuestionamientos se colocan en un plano eminentemente discursivo o si más bien se sitúan en un plano más complejo. En efecto, la complejidad actual en las relaciones internacionales y globales, nos permite mantener una posición no extrema en el sentido que se vive una etapa de transición en la cual, tanto elementos del pasado realista internacional, tal como se explicó previamente, como elementos del presente globalista postinternacional convergen en un momento histórico que proporciona la base de esos cambios citados pero que también se nutre de un desarrollo conceptual independiente que crea unas condiciones conceptuales que se orientan hacia una determinada dirección.

Por ello, al destacar los retos que tiene la política exterior de Venezuela en los tiempos globales es necesario preguntarse hasta que punto, los cambios que se han definido en cuestión afectan o no el buen desenvolvimiento de esa política. Por una parte, tal como se vio anteriormente, la política exterior de Venezuela se enmarca dentro de dos parámetros, uno referido su condición democrática y otro referido a una condición petrolera.

En cuanto a la condición democrática, Venezuela se ha beneficiado del ambiente a favor de la libertad y la democracia que se percibe en las relaciones internacionales. Si bien es cierto que no es fácil manejar un concepto genérico de democracia y metodológicamente utilizar un concepto que no tenga una referencia temporal y espacial, no es descartable el pensar que la democracia se ha constituido en una referencia en las relaciones internacionales así como otros temas derivados de éste, como el relacionado a los "derechos humanos" y el concerniente al "buen gobierno". Esta referencia fortalece el carácter democrático de Venezuela en sus dimensiones, tanto la de procurar las condiciones espaciales para su desarrollo, es decir un entorno facilitador, como el de promover los sistemas democráticos en el mundo y especialmente en América Latina.

Claro está, no es posible decir hoy que Venezuela es un ejemplo de democracia perfecta dada la fuerte tendencia desintegradora que tiene el sistema político venezolano. Por otra parte, la ahora traumática relación entre las variables independientes "ingreso petrolero" y "estabilidad política" permite que muchos autores reflexionen sobre la disminución del poder de convocatoria democrática que tiene el país en el mundo de hoy (Karl 1997).

En cuanto a la condición petrolera, la vinculación de este perfil con la política exterior y con los cambios globales, también se mantiene en un espacio moderado. La respuesta de los últimos años por parte de los sectores oficiales ha sido la de profundizar el carácter petrolero del país y reforzar los lazos con el socio comercial principal, los Estados Unidos. En este sentido, a diferencia de otros países latinoamericanos como Colombia y Chile que han tratado de diversificar sus productos de exportación y sus socios 
comerciales, Venezuela ha profundizado su relación con el petróleo y con los EE.UU.

En este trabajo se procura entonces relacionar esas condiciones con los efectos producidos por los cambios globales en una perspectiva teórica. Lo que se quiere es más que todo revisar los principales debates teóricos y metodólogicos que genera esta etapa en transición y sintonizarlos con la propia reflexión local. Para llevar a cabo este último proceso era indispensable ir más allá del acopio documental que proporciona el "state of the arts" de la disciplina y plantearse en primer lugar la necesidad de una revolución intelectual en la propia politología sobre la definición de la "polity venezolana” (Kuhn 1972). Este debe ser pues, nuestro punto de partida para la comprensión de una política exterior que debe ajustarse a la globalidad. Solo empezando de esa forma estaremos en condiciones de entender las respuestas contradictorias que hasta ahora se han tenido.

Este punto de partida se trató en este trabajo como la búsqueda de un enfoque alternativo para el estudio del sistema político venezolano, enfoque basado en la interrelación entre petróleo y política, enfatizando el papel que juega la renta petrolera en la formación de un determinado manejo polítco. Este determinado juego polítco, en donde el Estado venezolano es un actor principal condiciona la formación a su vez de una política exterior no flexible y que no ha experimentado grandes transformaciones.

Por ello no es descabellado plantear que en el caso venezolano, la estructura política-institucional de la política exterior es sustancialmente la misma aunque el contenido intelectual es diferente. Con esto se quiere decir que los pilares de la política exterior se mantienen firmes, democracia y petróleo, a pesar del cambiante panorama intelectual que muchas veces se utiliza para percibir, para definir una realidad que propiamente no se recoge con facilidad. Claro está, este panorama intelectual proviene de un debate que si bien no es ajeno no es necesariamente propio ni responde a procesos nacionales. Vale la pena destacar como ejemplo de lo dicho, la problemática sobre la globalización, sobre la integración y sobre la democracia, temas estos de carácter genérico sin tiempo ni espacio, como diría Skinner, que al confrontarse con una realidad internacional como la venezolana tropieza con innumerables obstáculos (Skinner 1998).

Es por ello, que las explicaciones "externas" no son lo suficientemente válidas para analizar un caso tan contradictorio. Me refiero a explicaciones "externas" en el sentido de una referencia a ese conjunto tan vasto y abstracto como es el que proviene del discurso de la globalización. Entonces, mientras no se ponga de relieve que en el plano de las "explicaciones internas" se puede lograr una pista para comprender las respuestas de Venezuela a los cambios globales, el trabajo estará parcialmente realizado. En suma, los elementos tratados nos exigen que le otorguemos a las variables internas un importante papel en este proceso de entender a la política exterior de Venezuela relacionada con un tiempo de transición. Pero para ello, es justo reconocer la importancia de esas explicaciones "locales" (Romero 1997).

En vista de todo ello, es perentorio recordar que en este trabajo se consideró en primer lugar hacer un estudio de las principales tendencias teóricas y metodológicas en el marco de la discusión sobre los cambios globales, para luego examinar las tendencias históricas en las relaciones internacionales y sus principales "áreas problemáticas". En tercer término se considero el perfil del sistema polítco venezolano, haciendo hincapié en las posibilidades de nuevas aproximaciones al tema, para luego en cuarto lugar, definir las potencialidades teóricas y prácticas de una política exterior a la que se le reclama respuestas ante las transformaciones actuales.

El ejercicio no ha sido fácil, ni era de esperarse, cuando de lo que se tratas es de formular una respuesta que provenga de nuestras propias condiciones y que evite en la medida de lo posible repetir consideraciones generales y genéricas tan de moda en los circuitos intelectuales y de decisores en el ámbito internacional. En este razonamiento se destacan tres elementos vitales: diferencias, temporalidad y identidad.

Podemos empezar por el primer elemento, las diferencias. Cabe preguntarse, ¿cuál es lo propio de la política exterior de Venezuela con respecto al resto de las políticas exteriores de los países latinoamericanos?, en segundo lugar, ¿que elementos surgen a la hora de condicionar una determinada conducta?; en tercer lugar, ¿cuales son los elementos que sustancian una identidad venezolana?

Estas, y quizás otros interrogantes de este mismo nivel, constituyen un campo fructífero, un terreno fértil para investigaciones futuras.

\section{BIBLIOGRAFÍA}

\section{A. Libros}

Almond, Gabriel A: A Discipline Divided. Schools and Sects in Political Science. London: Sage Publications, 1990.

ÁlvareZ, Angel (Coordinador): El Sistema Politico Venezolano: Crisis y Transformaciones. Caracas: Instituto de Estudios Políticos, UCV, 1996.

BAPTISTA, Asdrúbal: Teoria Económica del Capitalismo Rentista. Economia, Petróleo, Renta. Caracas: Ediciones IESA, 1997.

BARBÉ, Esther: Relaciones Internacionales. Madrid: Tecnos, 1995.

Begler, Gene: La Política y el Capitalismo de Estado en Venezuela. Madrid: Editorial Tecnos, 1981.

BlanCO, Carlos: Venezuela, Del Siglo XX al Siglo XXI: un proyecto para construirla. Caracas: Editorial Nuevas Sociedad, 1993.

BLASIER, Cole: The Hovering Giant: U.S Responses to Revolutionary Change in Latin America. Pittsburgh: Pittsburgh University Press, 1976.

BOND, Robert: Contemporary Venezuela and its Role in International Affairs. New York: New York University Press, 1977.

Cámara Venezolana-Americana de Comercio e Industria, VENAMCHAM, Versiones Taquigráficas Varias. Caracas: VenAmCham, 1992-1995.

CARDOzO de Da Silva, Elsa: Latinoamérica en Transición. En Busca del Aleph. Caracas: Editorial Panapo, 1995.

CARDOZO de Da Silva: Continuidad y Consistencia en Quince Años de Política Exterior Venezolana, 1969-1984. Caracas: CDCH-UCV, 1992.

Consalvi, Simón Alberto, El Perfil y la Sombra. Caracas: Tierra de Gracia Editores, 1997.

Comunidad Andina, Secretaria General: 28 Años de Integración Andina. Un Recuento Histórico. Lima: Comunidad Andina, 1997.

Domínguez, Jorge I (Editor): Economic Issues ad Political Conflict. U.S-Latin American Relations. London: Butterworth Scientific, 1982. 
Domínguez, Jorge (Editor): International Security and Democracy. Latin America and the Caribbean in the Post - Cold War Era. Pittsburgh, Pittsburgh University Press, 1998.

Dougherty, James E.; Pfalzgraff, Robert L.: Teorias en Pugna en las Relaciones Internacionales. Buenos Aires: GEL, 1995.

Ewell, Judith: Venezuela and the United States. From Monroe's Hemisphere to Petroleum's Empire. Athens: The University of Georgia Press, 1996.

FranCo, Andrés (Editor): Estados Unidos y los Paises Andinos, 19931997. Poder y Desintegración. Santafé de Bogotá: Centro Editorial Javeriana, CEJA, 1998.

GAMARRA, Eduardo: Entre la Droga y la Democracia. La Paz: ILDIS, 1994.

Elliot, John H.: National and Comparative History. An Inaugural Lecture Delivered Before the University of Oxford on 10 May 1991. Oxford: Clarendon Press, 1991.

España, Luis P., y Manzano, Osmel: Venezuela y su Petróleo: El Origen de la Renta, Caracas: Centro Gumilla, 1995.

Franco, Andrés: Las Relaciones de los Países Andinos con Washington. Santafé de Bogotá: Universidad Javeriana, 1997.

Hillman, Richard y de DA Silva, Elsa CARDOZO (comps): De Una a Otra Gobernabilidad, El Desbordamiento de la Democracia Venezolana. Caracas: Universidad Central de Venezuela, Fondo Editorial Trópikos, 1997.

HobSBAwn, Eric J.: Nations and Nationalism. Cambridge: Canto.Cambridge University Press, 1991.

Holt, Robert y John E. Turner: The Methodology of Comparative Research. New York: The Free Press, 1970.

Hoffman, Stanley: Teorias Contemporáneas sobre las Relaciones internacionales. Madrid: Tecnos, 1963.

Holm, Hans-Henrik y Sorensen George (editors): Whose World Order?. Uneven Globalization and the End of the Cold War. Boulder, Colorado: Westview Press, 1995.

Instituto de Estudios Políticos: La Agenda de la Política Exterior de Venezuela. Caracas: IEP/UCV, 1983.

IRELA: Informe de Conferencia "Perspectivas para las Relaciones de la Unión Europea con América Latina y el Caribe”. Madrid: IRELA, 1997.

IRELA Dossier n"61: El Mercosur: Perspectiva de un Bloque Emergente. Madrid: IRELA, 1997.

IRELA: La Unión Europea y el Grupo de Río. La Agenda Birregional. Documento DB - GRIO 97. Madrid: IRELA, agosto, 1997.

JANOS, Andrew C.: Politics and Paradigms. Changing Theories of Change in Social Sciences. Stanford: Stanford University Press, 1986.

Johnson, Nevil: Los Limites de la Ciencia Politica. Tecnos: Madrid, 1991.

KarL, Terry Lynn: The Paradox of Plenty. Oil Booms and Petro-States Berkeley: University of California Press, 1997.

KeOHANE, Robert y Joseph NyE (editors): Transnational Relations and World Politics. Cambridge: Harvard University Press, 1973

Keohane, Robert y Joseph NyE: Power and Interdependence. Cambridge: Harvard University Press, 1977.

Kunn, Thomas S: The Structure of Scientific Revolutions. Chicago: University of Chicago Press, 1970.

Lanzeta M., Mónica (Coordinadora): Agenda de Largo Plazo de la Relación Colombo-Venezolana. Santafé de Bogotá: TM Editores, CAF, Cámara de Comercio e Integración Colombo-Venezolana, 1997.

Levine, Daniel: Conflict and Political Change in Venezuela. Princeton: Princeton University Press, 1973.

Leycegui, Beatriz, William B. P. R. Robson y Dhalia SteIn (Coord.): Comercio a Golpes. Las Prácticas Desleales del Comercio Internacional Bajo el TLCAN. México: ITAM, 1997.

MALlOY, James (editor): Authoritarianism and Corporatism in Latin America. Pittsburgh: Pittsburgh University Press, 1977.

Martín, Gustavo: Las Ciencias Sociales: entre la epistemología y la deconstrucción. Caracas: Fondo Editorial Tropikos-Ceap. FACES, 1995.
MarTz, John y Dave Myers (Editors): Venezuela: the Democratic Experience. New York: Preger Publishers, New York, 1977.

Mc Coy, Jennifer, Andrés Serbin, Wiliam C. Smith and Andrés Stambouli: Venezuelan Democracy Under Stress. New Brunswick: Transaction Publishers, 1994.

Michelmann Hans J.; Soldatos, Panayotis: Federalism and International Relations. The Role of Subnational Units. Oxford: Clarendon Press, 1990.

Ministerio de Estado para las Relaciones entre el EjeCutivo Nacional y el Congreso de la República, Mesa Redonda: Aportes para un Plan Estratégico Legislativo (1997-1998). Caracas: Colección nº 2. Caracas, S/E, 1998.

Ministerio dE RELACIONES EXTERIORES DE VENEZUELA: Libro Amarillo. Caracas: M. de R.R.E.E., años 1993, 1994, 1995 y 1996.

MoORE Jr., Barrington: Los Origenes Sociales de la Dictadura y la Democracia. Barcelona: Ediciones Península, 1973.

Morguenthau, Hans: La Política entre las Naciones. La lucha por el poder y por la Paz. Buenos Aires: GEL, 1986.

NACIONES UNIDAS, CEPAL: Panorama de la Inserción Internacional de América Latina y el Caribe. Santiago de Chile: CEPAL, 1996.

NIEBUHR, Reinhold: Cristianity and Power Politics. New York: Charles Scribner's and Sons, 1940.

NisBet, Robert: Historia de la Idea del Progreso. Barcelona, Gedisa Editorial. Segunda Edición, 1991.

O'Donnell, Guillermo y Philipppe Schmitter: Conclusiones Tentativas sobre las Democracias Inciertas. Colección: Transiciones desde un Gobierno Autoritario, n” 4. Buenos Aires, Paidós, 1986.

O'Donnell, Guillermo: Modernization and Bureaucratic-Authoritarianism: Studies in South American Politics. Berkeley: University of California Press, 1973.

Olson, Mancur: The Rise and Decline of Nations. New Haven: Yale University Press, 1982.

OrganiZACIÓN DE ESTADOS AMERICANOS, OEA: Documentos de la XXXIV Asamblea. Washington: OEA, 1996.

Ormerod, Paul: The Death of Economics. London: Faber and Faber, 1995.

Petróleos de Venezuela, PDVSA: Informe Anual 1996. Caracas: PDVSA, 1997.

PÉrez S., María Sol: Petróleo, Cultura y Poder en Venezuela. 1993. Caracas: Monte Avila Editores Latinoamericana, 1993.

Ramírez, Socorro; RestrePO, Luis Alberto (Coord.): Colombia: entre la Inserción y el Aislamiento. Santafé de Bogotá: Siglo del Hombre Editores, IEPRI, Universidad Nacional, 1997.

Ramos, Eira (Coord.): América Latina en la Encrucijada. Los Nuevos Desafíos a la Integración Regional. Caracas: Ediciones FACES/ UCV, 1997.

ReInA, José Luis (Compilador): América Latina a Fines de Siglo. México, C.N.C.A, F.C.E, 1995.

REY, Juan Carlos: La Democracia Venezolana y la Crisis del Sistema Populista de Conciliación. Madrid: Centro de Estudios Constitucionales, 1991.

REY, Juan Carlos: El Futuro de la Democracia en Venezuela. Caracas: IDEA, Serie Estudios, 1989.

REY, Juan Carlos: Ensayos de Teoria Politica. Caracas: Editorial Ateneo de Caracas- Editorial Jurídica Venezolana, 1980.

Rodríguez G., Irene: El Petróleo en la Historografía Venezolana. Caracas: FACES-UCV, 1974.

Romero, Anibal: Disolución Social y Pronóstico Político. Caracas: Editorial Panapo, 1997.

Romero, Carlos A.: La Descentralización Politica en Venezuela y la Politica Exterior. Caracas: U.C.V, 1998.

Romero, Carlos A.: Reforma y Política Exterior. Caracas: INVESPCOPRE - Nueva Sociedad, 1992.

Rosenau, James N.: Turbulence in World Politics. A Theory of Change and Continuity. New York: Harverter-Wheat Sheak, 1990.

Rosenau, James y Ennst OtTo Czempiel: Governance without Government. Order and Change in World Politics. Cambridge, Cambridge University Press, 1992. 
RudolPh, Joseph y Robert J. ThOMPSON: Politica Etnoterritorial. Barcelona: Ediciones Pomares-Corridor, SA, 1992.

SCHELl, Jonathan: The Fate of the Earth. London: Picador, 1982.

Schelling, Thomas: The Strategy of Conflict. Oxford: Oxford University Press, 1963.

SCHELling, Thomas: Arms and Influence. New Haven: Yale University Press, 1966.

Seligson, Mitchell y John T. PASsé S.: Development and Undervelopment. The Political Economy of Global Inequality. Boulder: Colorado, Wetview Press, 1998.

Serbin, Andrés, Andrés Stambouli, Jennifer Mc Coy, William Smith (Editors): Venezuela: La Democracia Bajo Presión. Caracas: INVESP, North-South Center, University of Miami, Editorial Nueva Sociedad, 1997.

Sistema Económico Latinoamericano (SELA): Hacia un Área de Libre Comercio de las Américas. Caracas: SELA. INF.- 97/3 ALCA, 1997a.

Sistema Económico Latinoamericano (SELA): El Buen Gobierno y el Fortalecimiento de la Sociedad Civil. Notas desde la Perspectiva de América latina y el Caribe. Caracas: SELA, SP/DRE/DT - N 1-97, 1997b.

Sistema ECONÓmico Latinoamericano (SELA): La Ayuda de los Países Industrializados y los Organismos Económicos internacionales (OMC, Banco Mundial, FMI). Caracas: SELA, SP/DR, D. n 1697, 1997.

Sistema Económico Latinoamericano (SELA): Tendencias y Opciones en la Integración de América Latina. Caracas: SP/CL/ XXIII.O. D. n 8-97, 1997 d.

SKINNER, Quentin: Liberty Before Liberalism: Cambridge, Cambridge University Press, 1998.

SMith, Peter H. (Editor): The Challenge of Integration. Europe and the Americas. New Brunswick: Transaction Books, 1992.

Toro Hardy, Alfredo: El Desafio Venezolano. Cómo Influir las Decisiones Politicas Estadounidenses. Caracas: Instituto de Altos Estudios de América Latina, Universidad Simón Bolivar, 1988.

TORTORA, Manuela: Politica Social y el ALCA. SELA, Caracas, SP DRE/D. N"20-98. 1998a.

Touraine, Alain: Crítica a la Modernidad. Buenos Aires: Fondo de Cultura Económica, 1992.

Truyol y Serra, Antonio: La Sociedad Internacional. Madrid: Alianza, 1974.

Urbaneja, Diego Bautista: Pueblo, Petróleo y Politica. Caracas: CEPET, 1990.

Tugwell, Franklin: La Politica del Petróleo en Venezuela. Caracas: Monte Avila Editores, 1975.

VITAL, David: The Inequality of States. Oxford: Clarendon Press, 1971.

WALKeR, R. B. J.: Inside/Outside. International Relations as Political Theory. Cambridge: Cambridge University Press, 1993.

\section{B. Artículos}

Alvarez, Angel E: "El Paradigma de Acción Racional Aplicado al Análisis de las Decisiones del Sistema Político Venezolano, en el Caso del Diferendo Límitrofe con Colombia”. Caracas, POLITEIA, n¹0, 1981, pp. 51-84.

Arellano, Félix Gerardo: "La Integración Económica y los Paradigmas en América Latina”. Capítulos del SELA 49, Enero - Marzo, 1997, pp. 10-29.

Bonilla, Adrián: "Las Relaciones entre Ecuador y Estados Unidos: entre el Sobresalto y la Rutina". En: Andrés Franco (Editor), Estados Unidos y los Países Andinos: 1993 - 1997: Poder y Desintegración. Santafé de Bogotá: Centro Editorial Javeriana (CEJA), 1998.

BuZAN, Barry: "From International System to International Society. Structural Realism and Regime Theory Meet the English School". International Organization. Vol. 47, n"3, Summer 1993, pp. 327 352.
BRUnNER, José Joaquín: "Tradicionalismo y Modernidad en la Cultura Latinoamericana”. En: José Luis Reyna (Compilador), América Latina a Fines de Siglo..., pp. 276-306.

CAPriles M., Ruth: "Racionalidad de la Corrupción en Venezuela". Caracas, Politeia n"16, Instituto de Estudios Políticos UCV, 1993, pp. 207-240.

CÁRdEnas E., Emilio: "El Camino hacia la Teoría de las Relaciones Internacionales" (Biografía de una disciplina). Revista Mexicana de Ciencia Política. Vol. XVI, n” 63, 1971.

Cardozo de Da Silva, Elsa: "Venezuela: política exterior para la gobernabilidad democrática”. En: Richard Hillman, Elsa Cardozo de Da Silva, Op. Cit, 75-122.

Cardozo de Da Silva, Elsa: "Repensando Politicamente el MERCOSUR desde Venezuela". Política Internacional, vol. x, n'12, abril-Junio, 1996, pp. 9 - 13.

CASTAÑEDA, Jorge: "Razones para el Escepticismo". El Nacional, (Caracas), 18 de abril de1998, p. A/7.

COMISIÓN DE ANÁLISIS Y RECOMENDACIONES SOBRE LAS RELACIONES ENTRE COLOMBIA Y LOS ESTADOS UNIDOS: "Colombia: Una Nueva Sociedad”. Análisis Político. Santafé de Bogotá, Julio, 1997.

DURÁN, Martín: "Introducción al Pensamiento Petrolero Venezolano". Papel de Trabajo, 1998.

ESPINASA, Ramón: "Petróleo y Desarrollo”...

ESPINASA, Ramón: "Política Petrolera y Desarrollo Económico”. Papel de Trabajo. Caracas, PDVSA, 1997.

Fazio VengoA, Hugo: "América Latina y los Procesos de Globalización: oportunidades, dilemas y desafíos. En: Socorro Ramírez y Luis Alberto Restrepo, (Coordinadores)., Colombia: entre la Inserción y el Aislamiento. Santafe de Bogotá. Siglo del Hombre Editores, IEPRI, Universidad Nacional, 1997, pp. 21 - 45.

FERnÁnDEZ, Wilson: "El Mercosur ante el Nuevo Siglo: Tendencias y Perspectivas". Papel de Trabajo presentado en LASA 97. Guadalajara, México, 1997.

Franco, Andrés: "La Cooperación Fragmentada Como Una Nueva Forma de Diplomacia. Las Relaciones entre Colombia y los Estados Unidos en los Noventa". En: Andrés Franco (1997), Estados Unidos y los Países Andinos 1993 - 1997. Poder y Desintegración. Santafé de Bogotá: Centro Editorial Javeriana, CEJA, pp. 37-80.

GAmARRA, Eduardo: "Las Relaciones entre Estados Unidos y Bolivia durante el Gobierno de Gonzalo Sánchez de Lozada”. En Andrés Franco (Editor), Estados Unidos y los Países Andino, 1993 - 1997. Poder y Desintegración. Santafé de Bogotá: Centro Editorial Javeriana, CEJA, 1998.

GARAY, Luis Jorge: "Regionalismo Abierto e Integración en las Américas. A Propósito del Caso del Grupo Andino”. En: Mónica Lanzetta, Op. Cit, pp. 419-530.

García P., Manuel: "Ensayo de una Teoría de los Símbolos Políticos”. En: García Pelayo, Manuel, Obras Completas..., pp. $987-$ 1031.

García P., Manuel: "Estudio Preliminar" del libro de Giovanni Botero: La Razón de Estado y Otros Escritos. Colección: Antología del Pensamiento Político. Vol III. Caracas, IEP-UCV, 1962.

Guerón, Carlos: "La Doctrina Betancourt y el Papel de la Teoría en Política Exterior". Politeia n. "1. Caracas, IEP - U.C.V, 1972, pp. 231-243.

HeIn, Wolfgang: "El Fin del Estado- Nación y el Nuevo Orden Internacional". Las Instituciones Políticas en Perspectiva”. Nueva Sociedad, n"132, pp. 83-99.

HeY, Jeanne: "Foreign Policy Options Under Dependence. A Theoretical Evoluton with Evidence from Ecuador". Journal of Latin American Studies, n' 25, 1993, pp. 543-574.

SALE, John Kinkaid: "Constitutent -Diplomacy in Federal Polities and the Nation States: conflict and cooperation”. En: Michelmann Hans J.; Soldatos, Panayotis., Federalism..., pp. 54-76.

Holt, Robert T. y John M. Richarson Jr: "Competing Paradigms in Comparative Politics”. En: Holt, Robert; Turner. John E., The Methodology..., pp. 21-72. 
Huntington, Samuel P.: ¿"The Clash of Civilizations?. John Olin Institute for Strategic Studies Working Paper n 44, January 1993. Cambridge, Harvard University, 1993.

Hurrel, Andrew: "Regionalism in Theoretical Perspective". Papel de Trabajo. Oxford, 1994.

JOSKO DE GUERÓN, Eva: "La formulación y ejecución de la política exterior como un problema en la agenda". En: Instituto de Estudios Políticos, Op. Cit.

Kaplan, Morton: "The Great Debate: Traditionalism vs Science in International Relations". World Politics. Vol. 19, n"1, pp. 1-20.

KELLY, Janet: "Venezuelan Foreign Economic Policy and the United States". En: Jorge Domínguez (Editor), Economic Issues and Political..., pp. 107-141.

Kornblith, Mirian: "Crisis y Transformación del Sistema Político: Nuevas y Nuevas Reglas de Juego". En: Angel Alvarez (Coordinador), Op. Cit.

Krugman, Paul: "Los Ciclos en las Ideas Dominantes con Relación al Desarrollo Económico". Desarrollo Económico, Vol. 36, n" 143, octubre-diciembre 1996, pp. 715-731.

Lander, Luis: "Apertura Petrolera en Venezuela". Papel de Trabajo presentado en LASA 97, Guadalajara, México, 1997.

LIPSET, Seymour Martin: "Valores e Instituciones Estadounidenses desde una Perspectiva Occidental Comparada". Política y Gobierno. México, CIDE. n² 2, segundo semestre de 1996, pp. 361-377.

LIPSET, Seymour Martin: "Some Social Requisites of Democracy Economic Development and Political Legitimacy". The American Political Science Review. Vol. 53, n" 1 (march 1959), pp. 69-105, p. 54.

MARTz, John: "Venezuela's Foreign Policy Toward Latin America". En: Robert Bond., Contemporary Venezuela and Its Role in International Affairs. New York. New York University Press. 1977.

MC CoY, Jennifer: “¿Venezuela; Crisis de Confianza?”. En: Andrés Serbin et.al., op.cit, pp. 9-26.

MENA, Julia: "Las Relaciones Internacionales y la Economía Mundial". Caracas, mimeo, 1997.

Morgenthau, Hans: "Common Sense and Theories of International -Relations", Journal of International Affairs, n 2, 1967.

POWELL, Robert: "Anarchy in International Relations Theory: the Neorealist-Neoliberal Debate”. International Organization. Vol. 48, n"2, Spring 1994, pp. $313-344$.

MYERS, David J: "Perceptions of a Stressed Democracy: Inevitable Decay or Foundation for Rebirth?”. En: Jennifer Mc Coy, Andrés Serbin, William C. Smith and Andrés Stambouli: Venezuelan Democracy Under Stress..., pp. 107-138.

PrIES, Ludger. Papel de Trabajo presentado en LASA 97, Guadalajara, México, 1997.

Quejeiro, Rogelio: "El Tratamiento Multilateral de las Políticas Comerciales y el Derecho de la Competencia". Revista de la Facultad de Ciencias Jurídicas y Políticas, n"104, 1997, pp. 307 378.

Ramos, Eira: "Globalización, Soberanía y Seguridad". Caracas, Mimeo 1997.

Rivas Funes, María José: "Política y Anti-Política". Sistema. Revista de Ciencias Sociales. Madrid, no 129, noviembre de 1995, pp. 121133.

RODRIK, Dani: "Sense and Nonsense in the Globalization Debate" Foreign Policy. Summer 1997, pp. 19-37

RojAs, Laura: "Aspectos Económicos de la Política Exterior de Venezuela". En:

Romero, Aníbal: "La Situación Estratégica de Venezuela". Política Internacional. Vol Y. $\mathrm{N}^{\circ} 1$, pp. 6-14

Romero, Carlos A: Reforma y Política Exterior. Caracas, Nueva Sociedad-Invesp, 1992, pp. 145-172.

Romero, Carlos A.: "Planos y etapas de la Política Exterior de Venezuela”. Revista de la Facultad de Ciencias Juridicas y Políticas. Año XXXV, n 74, UCV, Caracas, 1990.
Romero, Carlos A.: "Relaciones Internacionales y Política Exterior de Venezuela". En: Carlos Blanco (coordinador), Venezuela, Del Siglo XX al Siglo XXI: un proyecto para construirla. Caracas: Editorial Nueva Sociedad, 1993, pp. 121 - 132.

Romero, Carlos A.: "América Latina: el Reto del Siglo XXI. Sintesis: Madrid, IRELA, n²5, enero-junio 1996, pp. 121-133.

ROMERO, Carlos A.: "Las Relaciones entre Venezuela y los Estados Unidos durante la Era Clinton: coincidencias estratégicas y diferencias tácticas". En: Andrés Franco, Op. Cit,

Romero, Carlos A.: "Perspectivas de Venezuela en la Integración Latinoamericana”. En: Ministerio de Estado..., pp. 73-82.

ROMERO, Carlos A.: "Las Relaciones entre Venezuela y Estados Unidos: Realidad Histórica u Opción Política?”. Política Internacional. Vol. I, n², Abril-Junio 1986, pp. 11-14.

Romero, Carlos A.: "La Influencia de Tocqueville en la Visión Norteamericana del Sistema Político Venezolano". Politeia n 12. Instituto de Estudios Políticos, UCV, 1988, pp. 43-46.

Romero, Carlos A.: "EE.UU- Venezuela". Después de la Visita". Borrador de artículo, 1998.

Rosenau, James: "La Teoría de la Complejidad y los Asuntos Mundiales". Nueva Sociedad, n 148, marzo-abril 1997, pp. 7083.

Rossini Martín, Elba y Jaime Luis Socas: "La Orimulsión: Un Complemento para la Industria Petrolera Venezolana". Política Internacional. Año X, n 42, Abril-Junio 1996, pp. 22-28).

SalamanCA, Luis: "Crisis de la Modernizacióny Crisi de la Democracia en Venezuela; Una Propuesta de Análisis. En: Angel Alvarez (Coordinador): El Sistema Politico Venezolano..., pp. 239-351.

SÁNCHEZ BAjO, Claudia: "The Mercosur Agenda of Trade and Industrial Policies". Papel de Trabajo presentado en LASA 97. Guadalajara, México, 1997.

SCOTt PALMER, David: "Las Relaciones entre Estados Unidos y Perú Durante los Gobiernos del Presidente Clinton”. En. Andrés Franco (1998) (Editor), Estados Unidos y los Países Andinos 1993 - 1997. Poder y Desintegración. Santafé de Bogotá: Centro Editorial Javeriana, CEJA, pp. 113 - 139.

SCHMitTer, Philippe: "Las Sendas del Desarrollo Político de América Latina”. Estudios Andinos. Vol. III, n 8, pp. 49-70.

SMITH, Peter: "Introduction. "The Politics of Integration: Concepts and Themes". En: Peter H. Smith (Editor), Op. Cit.

Sistema ECONÓMICO LATINOAMERICANO, SELA: "Belo Horizonte: La Compleja Construcción del ALCA". SELA; Boletín sobre Integración de América Latina y el Caribe. N 4, Mayo de 1997. pp. 1-2.

TORTORA, Manuela: "Manual del Negociador Económico de la Próxima Década”. Capitulo del SELA, 49, Enero - Marzo 1997b, pp. 7 - 12.

TulCHIN, Joseph: "Reflections on Hemispheric Relations in the 21 Century". Journal of Interamerican Studies and World Affairs. Miami, Vol. 39, n 1, Spring 1997, pp. 33-43.

TulCHIN, Joseph: "Reflexiones sobre las Relaciones Hemisféricas en el Siglo XXI. Síntesis. Madrid. N²5, Enero - Junio, 1996, pp. $125-132$.

VACCHINO, Juan Mario: "Hemispheric Negotiations: Questions and Options”. Capitulos del SELA, n49, enero-marzo 1997, pp. 87 96.

VAnderdis, Miguel: "Positivismo, Populismo y Racionalidad" Politeia, $\mathrm{n}^{\circ} 16$, Instituto de Estuduios Políticos, UCV, 1993, pp. 207-240.

\section{Monografías}

Bravo, Mauricio: El Narcotráfico en Venezuela. Monografía. Caracas, s/e. 1996.

LANDER, Luis E.: Apertura Petrolera en Venezuela. Monografía. Caracas, s/e, 1997. 


\section{RESUMEN}

El mundo ha avanzado hacia la globalización, lo que exige que América Latina, con poca relevancia internacional y con una situación económica crítica, busque ajustarse a las nuevas exigencias internacionales mediante "la desregulación y la coordinación económica”. También se hace prioritaria la búsqueda de la integración regional tanto a nivel público como privado a través de instituciones como Mercosur y la Comunidad Andina de Naciones.

Este artículo plantea las incidencias de la globalización y la integración en la política exterior venezolana y los mecanismos a aplicar para ajustarse al nuevo modelo mundial. Tres son los puntos prioritarios en este sentido: los cambios globales, el petróleo y la política exterior.

La situación de Venezuela como país proveedor de petróleo a Estados Unidos le ha permitido ser conservador en sus posiciones y asumir la apertura económica de forma más discreta al resto de países de la región. La democracia es otro tema que rodea las relaciones internacionales, especialmente lo relativo a los derechos humanos y al buen gobierno, y del cual Venezuela se beneficia al procurar un espacio idóneo para su desarrollo.

Palabras clave: Globalización, relaciones internacionales, petróleo, integración, política exterior.

\section{ABSTRACT}

The world has moved towards globalization, which means that Latin America, that has low international leverage and a critical economic situation, has to search for an adjustment to the new international demands by means of "deregulation and economic coordination". It is also a priority to pursue the regional integration at the private and public levels through institutions such as Mercosur y la Comunidad Andina de Naciones.

This article poses the incidences of globalization and integration in the Venezuelan international policy, as well as the mechanisms of adjustment to the new world order. Three elements are pointed out as priorities: the global changes, the petroleum, and the international policy.

The situation of Venezuela as a US supplier of petroleum has permitted this country to be more conservative in its positions and to assume the economic opening in a more discrete fashion as compared to the rest of the countries in the region. Democracy is another issue surrounding the international relations, specially in what refers to human rights and good government, and from which Venezuela benefits when pursuing the appropriate developmental environment.

Key words: Globalization, international relations, petroleum, integration, international policy.

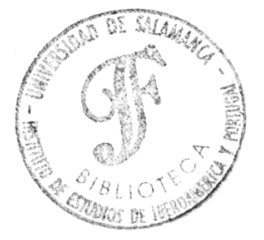




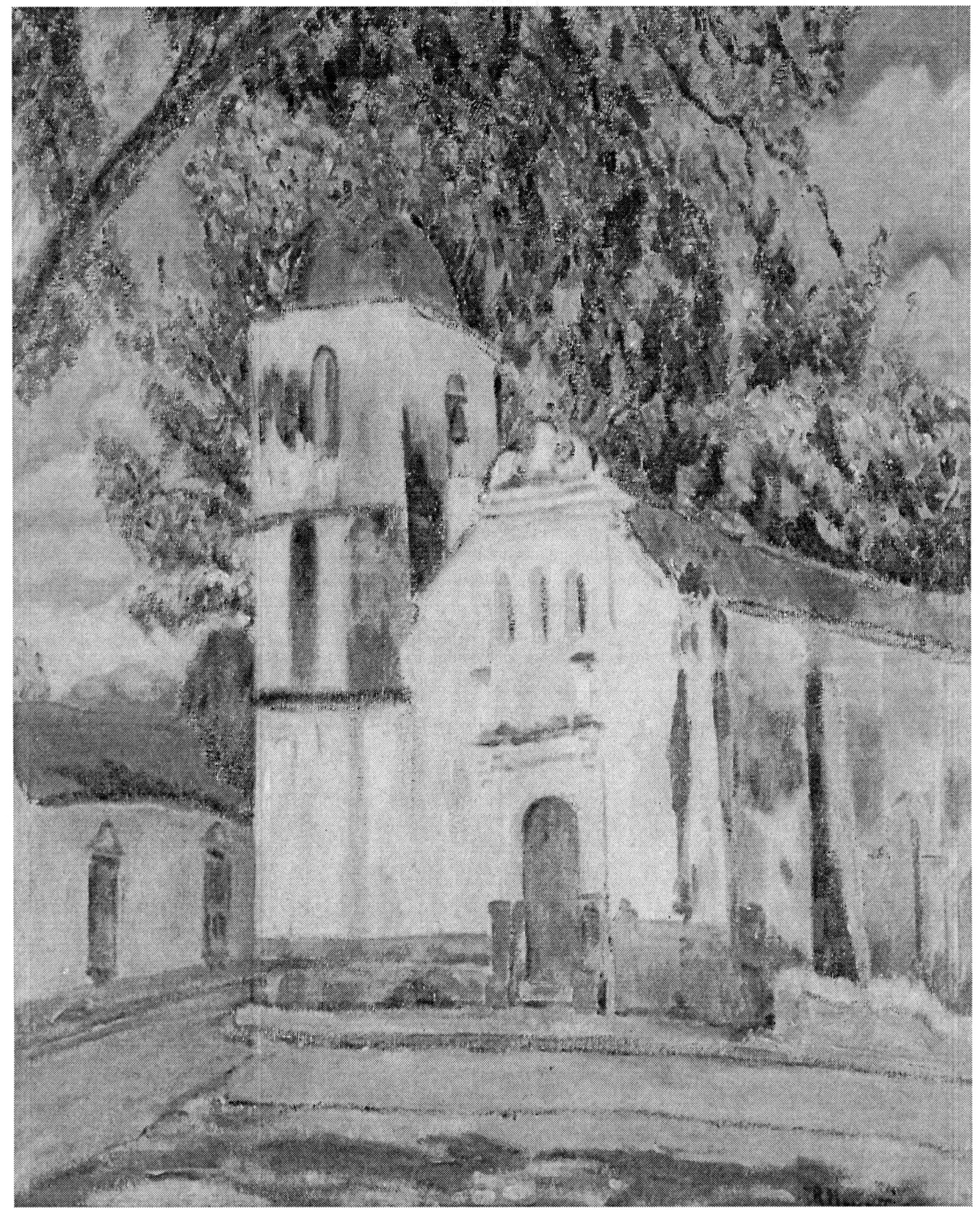

"Capilla de Naguanagua”, Rafael Monasterios 